Convention on the Conservation of Migratory Species of Wild Animals

CMS

$3^{\text {rd }}$ Meeting of the Sessional Committee of the CMS Scientific Council (ScC-SC3)

Bonn, Germany, 29 May - 1 June 2018

UNEP/CMS/ScC-SC3/Inf.8

REPORT OF THE CMS WORKSHOP ON

CONSERVATION IMPLICATIONS OF ANIMAL CULTURE AND SOCIAL COMPLEXITY

(Submitted by the Secretariat) 


\section{Convention on the Conservation of Migratory Species of Wild Animals}

\section{$1^{\text {ST }}$ CMS WORKSHOP ON CONSERVATION IMPLICATIONS OF ANIMAL CULTURE AND SOCIAL COMPLEXITY}

Parma, Italy, 12-14 April 2018

\section{REPORT}

The Government of the Principality of Monaco were recognized as Champion Plus for their generous

CHAMPION support and commitment towards marine species 


\section{Summary of Recommendations}

\section{Overarching Recommendations:}

- Conserving cultural repositories and capacities (e.g. cultural inheritance systems) should be integrated into the development of IUCN, CMS and other conservation and management strategies, including but not limited to assessing populations and designating units to conserve, in situ monitoring, human-wildlife conflict, reintroduction programmes, etc.

- Education and raising awareness about the value of conserving cultural diversity should be a priority of the CMS initiative on culture and social complexity in animals.

- Empirical evidence of behavioural diversity, social learning networks and migratory behaviour and connections should be collected for taxa of relevance to CMS.

- Theoretical models of social transmission and population level effects should be developed to inform mitigation and investigate future scenarios for conservation issues for taxa of relevance to CMS.

- It was further recommended that cataloguing the dimensions of cultural diversity in animals may be important to assist in:

- identifying and conserving cultural capacities and repositories

- driving conservation actions and strategies.

Potential key dimensions of cultural traits of note:

- What is the domain of trait? foraging, tool use, migration, habitat utilization, communication, social interactions, etc.

- Who performs the behaviour? Is it specific to a particular age/sex class, aspects of age-structure populations (demography), social status within social units, social connectedness?

- What is the spatial occurrence of the trait? E.g., is it a proportion of the range of population /sub-species.

- What is the temporal nature of the trait or the information it conveys? Does the trait have temporal variables, what is its frequency of occurrence and does it show longterm persistence, does the trait convey long-term (e.g., migratory destination) or ephemeral (e.g., food source) information.

- What is the function of the trait? Does it relate to reproduction, growth/maintenance, social relationships, etc. - or no obvious adaptive value?

- Patterns of transmission: evidence of form or forms of cultural transmission, e.g. observational learning, teaching; vertical or horizontal transmission.

\section{Further recommendations arising from sub-group discussions:}

- Enhance communication around animal culture and social complexity, especially in areas with human-wildlife conflict (HWC)

- Utilize animal - and human - social learning to facilitate better conservation outcomes in HWC and other conservation management strategies.

- Move beyond counting numbers of individuals when assessing the conservation status of highly social species and the outcomes of conservation actions

- Cultural units should now be considered as potentially meriting conservation efforts, contrasting with the traditional focus on species, and on genetics (Table 3 provides suggestions for criteria that may be used to consider conservation strategies in culturally defined units)

- Consider the overall age and social structure of populations to maintain cultural capacity. 
- If particularly important classes of individuals can be identified (e.g. social brokers, matriarchs, individuals with resident knowledge), focus on protecting these individuals and connections.

- Where possible maintain population connections across the species' range.

- Identify important keystone "information source" species within wider species communities, and consider their impact on the conservation of target species.

- For reintroduction programmes:

- Wherever possible, individuals should be exposed to experienced conspecifics interacting with a range of stimuli that they are likely to encounter in the wild (e.g. conspecifics; foods; predators)

- Where cultural knowledge has been entirely lost in the wild, human tutors may need to be used to re-establish desired behaviour in the first instance

- In species that show parental care, intensive support should be provided to achieve breeding in reintroduced populations, so that future generations can learn from the most competent surviving conspecific parental models

- Programmes should take into account likely social learning biases - e.g. individuals may be more likely to learn from adults, or from resident individuals

- Programmes should monitor and maintain detailed data encompassing individuals' social interactions (e.g. social affiliations; exposure to human or conspecific models) and exposure to stimuli pre- and post-release

- Recognizing that culture is another aspect of biology that should be considered within existing conservation initiatives, it is recommended that the social learning and culture are integrated into efforts to:

i. $\quad$ assess populations and designate units to conserve

ii. $\quad$ assess the impact of introgression and hybridisation

iii. manage endangered populations and reintroduction schemes

iv. mitigation planning for environmental change and development

- Develop rapid assessment tools and emerging technologies to provide direct and indirect evidence of social transmission, migration routes, social networks, as well as anthropogenic effects on behaviour, informing conservation and management

i. Acoustics: passive acoustic monitoring (Wrege et al. 2017); acoustic identification of population units; autonomous recording with identification software (Zimmer 2011 Passive acoustic monitoring of cetaceans, Cambridge University Press)

ii. Biologging: movement and activity tracking; direct and indirect encounter mapping for social network building (Krause et al. 2013, Tr. Ecol. Evol. 28:541551; Kays et al. 2015, Science; Hussey et al. 2015, Science)

iii. Genetic and genomic techniques including eDNA and minimally-invasive sampling to identify kin groups, population structure and migratory connections (Carroll et al. 2018; Arandjelovic and Vigilant 2018)

iv. Stable isotopes, fatty acids and other biochemical makers to delineate population segments with distinct habitat use, as well as transmission patterns of foraging behaviour

v. Proxies of culture that can be assessed more easily. For example, in tool-using New Caledonian crows, the idea has been explored to rapidly map possible regional variation in foraging behaviour, using vocal dialects as 'markers' (Bluff et al. 2010, Biol. J. Linn. Soc.). the Pan African Programme: the Cultured Chimpanzee of the Max Planck Institute for Evolutionary Anthropology, is underway using camera traps, quantification of resource availability, and other rapid assessment techniques to survey further diversity of behaviour amongst chimpanzees across 40 African study sites, and has already revealed forms of behaviour previously unknown (Kuhl et al. 2016). 
Further, it was noted that whilst the efforts of CMS are focussed on migration across jurisdictions, the migration of some species, where the migration routes are contained within one nation, may warrant special attention. For example, there are some species where migration routes are entirely contained within one jurisdiction that show migratory behaviour that is likely to be influenced by social learning, and where some aspects of migration routes may represent cultural traditions. For example, several species of Australian bird, including but not restricted to Orange-bellied Parrots (Neophema chrysogaster) and Swift Parrots (Lathamus discolor), exhibit a high degree of sociality in foraging and migration patterns. It was noted that these species could be highlighted for future action by national authorities, and that research on these species could be useful and informative for the broader aims of understanding these process in species that do migrate across international jurisdictions (particularly since the total migration distance of the two examples given are probably of a longer absolute distance than of many migratory species that cross multiple national jurisdictions). 


\section{Report of the Workshop}

\section{A. Opening and Introductions}

The meeting opened with welcoming remarks from Giuseppe Notarbartolo di Sciara, Fernando Spina and Philippa Brakes, expressing gratitude to the hosts and sponsors of the workshop, the Appennino Tosco-Emiliano National Park, the Fondazione Monteparma, and the Principality of Monaco. They also thanked the many workshop participants who had made time in their busy schedules to contribute to the deliberations of the workshop.

\section{B. Background Presentations}

\section{CMS background}

\subsection{History, context and mandates for the workshop}

Heidrun Frisch-Nwakanma of the CMS Secretariat provided an overview of CMS, its objective, mechanisms, institutional framework and the context for the workshop. She explained that the Convention's interest in the subject had started in 2011, when Resolution 10.15 Global Programme of Work for Cetaceans requested the Scientific Council to investigate relevance of this emerging field of science to cetacean conservation. This had resulted in a workshop focusing mostly on cetaceans in 2014 and a first resolution being adopted on the issue the same year. In October 2017, at the $12^{\text {th }}$ Meeting of the Conference of the Parties to CMS (CMS COP12), this resolution had been revised and was now explicitly referring to animal culture, expanding the scope of work to all taxa covered by CMS.

The Expert Working Group on Animal Culture and Social Complexity, established in 2015 and working through an online workspace, was directed by CMS COP12 to "[d]evelop a list of priority species listed on the CMS Appendices for a comprehensive investigation of culture and social structure and commence more detailed analysis as appropriate, including for example developing a list of key factors that should be taken into consideration for effective conservation" (Decision 12.75 b.). To assist the Expert Working Group, the Secretariat was requested to convene this workshop, specifically with the aims of developing a list of key factors for identifying priority species and populations listed under CMS where social learning may influence their conservation, and to explore the opportunities for engagement across the CMS daughter agreements (Decision 12.76). The outputs of this workshop would accordingly go to the Expert Working Group, who would use them to fulfil their mandates, and report their findings to the Scientific Council, which would be responsible to make recommendations to the $13^{\text {th }}$ Meeting of the Conference of the Parties (Decision 12.77).

\subsection{CMS Scientific Council, species appendices and progress to date}

The Chair of the CMS Scientific Council, Fernando Spina, provided more detail on the role of the Scientific Council in this process to date and highlighted the definition of migratory species within the context of the Convention text which defines migration thus:

"Migratory species" means the entire population or any geographically separate part of the population of any species or lower taxon of wild animals, a significant proportion of whose members cyclically and predictably cross one or more national jurisdictional boundaries. 
He noted that the Convention's definition provides a geo-political perspective of a natural phenomenon, which includes cyclical dispersal across national jurisdictions, hence the inclusion of species such as gorillas on the appendices.

\section{Social learning and conservation across taxa: definitions, methods and relevance}

Philippa Brakes noted the challenges and opportunities associated with moving this work across taxa and provided some orientation for efforts to date. She highlighted the definitions used by the CMS Expert Working Group on culture and their use of the exclusionary process for assessing the plausibility that social learning, rather than ecological or genetic factors may be driving specific behaviour within a social group. As a starting point she suggested a number of factors which could be important for considering the conservation implications of various aspects of sociality including, ontogeny, social structure, social role and social learning mechanism.

\section{Conservation Priorities for CMS-listed Species}

\section{Sub-group discussions}

Facilitated by Mark Simmonds, participants then worked in four sub-groups to explore the following issues as they related to CMS:

- Worlds that collide: Human-wildlife conflict (HWC) and anthropo-dependence

- Wildlife sages: Conserving valuable cultural diversity in wildlife

- Socio-geography: Social learning, range recovery and migration, island populations

- Socio-vulnerability: Specialization versus ecological resilience

The groups recorded the outcome of their discussions in the following reports from each subgroup. More generally it was agreed that the goals of conservation were to (1) determine which aspects of biodiversity were in need of conservation; (2) identify and evaluate threats to biodiversity; and (3) establish means of mitigating these threats with the overarching aim of maintaining evolutionary or adaptive potential, which was the ability of species/populations to respond to selection by means of phenotypic or molecular changes (Eizaguirre and BaltazarSoares, 2014). Animal culture and the use and transfer of social information were highly relevant to each of these aims (Greggor et al. 2016).

Social learning of behavioural variants and potential resultant culture generated phenotypic diversity and influenced population viability, demography and evolutionary or adaptive potential by allowing adaptive information to spread through groups and between parents and offspring. Thus, cultural variation could be considered a crucial element of biodiversity to be conserved. In addition, cultural traits in some behavioural domains might be used as a proxy for assessing cultural traits in other domains that might be more challenging to measure in the wild (for example, measuring song or vocalizations mighty be easier or more efficient than measuring tool use). Culture could also lead to the promotion of isolation between groups, for example, between those that had distinct acoustic, migratory or foraging traditions.

In addition, an often-overlooked threat to biodiversity resulted from perturbations to patterns of cultural transmission that limit the acquisition of fitness-related knowledge and skills. Finally, by implementing protocols that maintained or in some circumstances even re-created channels for cultural transmission, we might help to maintain healthy populations or reestablish populations that had declined or even gone extinct in the wild. 


\section{GROUP A \\ Worlds that collide: Human-wildlife conflict (HWC) and anthropo-dependence}

\section{Scope}

While the overarching workshop theme was culture and social complexity, the sub-group focused discussions on social structure and social learning, as the substrate for culture to emerge.

The group discussed several ways in which "worlds that collide" occurred and focused on four of these: (a) the impact of socially learnt animal behaviour on human activities, more broadly termed "human wildlife conflict" (HWC), which included interactions such as crop raiding, and depredation of commercial fisheries or livestock; (b) human impacts on animal social structures and cultural traditions, which could have population-level consequences; (c) the influence of climate change on animal social learning and sociality; and (d) a lack of understanding of animal culture and social complexity which could confound conservation efforts.

Examples of these collisions included (see Table 1 for additional examples):

\section{a) Impact of socially learnt animal behaviour on human activities}

African elephants commonly foraged on crops wherever they co-occurred with farmers and cultivated food sources are usually preferred by elephants, even when wild food sources were plentiful. Electric fences might deter crop raiding, but they were extremely expensive to deploy and elephants could quickly learn techniques to break them, increasing maintenance costs. All elephants learned from each other, particularly young males which could learn raiding techniques from experienced older males, and which often raided in the company of close associates (Chiyo et al. 2012). While raiding defended farms, male elephants had been observed to guide and protect younger males from farm defenders. Experienced fence breakers served as a repository of knowledge and spread this behaviour among a population, exacerbating human-wildlife conflict. Similarly, in chimpanzees information on which crops were raided might also be socially learned (McLennan and Hocking 2014).

\section{b) Human influences on animal social structure and cultural traditions}

During fishing operations for tuna in the eastern tropical Pacific Ocean social disruption caused by repeated chase, encirclement, and release of dolphins might have negative impacts on survival and reproduction, which might impede population recovery, even in the absence of direct mortality (Wade et al. 2012). Pelagic dolphins were thought to live in fission-fusion societies in which small social units (e.g., mother-calf pairs, bonded adult females, nursery groups, juvenile sub-groups, male alliances) aggregated in large, dynamic schools. Tuna-purse seine operations might cause social separation of units or might disrupt the mating system (especially for species where few males controlled most mating opportunities, Perrin and Mesnick 2003);

c) Lack of understanding of animal culture and social complexity confounding conservation efforts

A lack of understanding of animal sociality might actually serve to contradict intended management objectives. Unselective lethal control of wolves had been shown to decrease pack stability and territory persistence, which increased the number of breeding pairs and 
resulted in compensatory numerical responses (predator density) by surviving wolves (Brainerd et al. 2008, Borg et al. 2014).

d) Influence of climate change on animal social learning and sociality

Global warming was a serious issue for lizards and had already resulted in population-level extinctions in many species (Sinervo et al. 2010). Lizards were capable of social learning (Noble et al., 2014) and their cognitive ability was affected by warming incubation environments (Amiel et al. 2017). Under global warming, lizards had a more restricted daily activity period and less opportunity to learn socially from conspecifics, which could impact on foraging success and information transfer about key environmental variables.

The group noted that such "collisions" generated conservation risk in two senses. First, when animal behaviour generated negative impacts on human activity (as in point (a) above) and second, when human activities generated negative impact on animal populations (points (b) - (d), see also Table 2). The former could include injury to humans or loss of income and could cause unfavourable attitudes towards animals and decrease interest in conservation. The latter mighty, directly or indirectly, disrupt animal social systems with negative impacts on survival and reproduction with resulting population-level consequences. The group determined that climate change issues were beyond the scope of these discussions, but found common issues with the remaining collisions: they highlighted the need for conservation interventions that considered site-specific human and animal context and the need to bring stakeholders together early. The group also discussed the definition of "conflict" including the distinction between "impacts" and "conflict" (see below).

We recognized that many other "worlds that collide" problems existed but were not addressed here. These included issues such as provisioning, in which animals became dependent on humans (such as Bottlenose Dolphins or bears; Foroughirad and Mann 2013; Kirby et al. 2016), reintroduction and rehabilitation, among others.

\section{Recommendations}

Recommendation 1. Enhance communication around animal culture and social complexity, especially in areas with human-wildlife conflict (HWC).

The group noted that resolving issues of human-wildlife conflict (HWC) was important because it would increase tolerance for animals and increase interest in their conservation. Ultimately, the goal was to move from "conflict" to "co-existence" scenarios with active intervention plans. The group discussed the importance of the need to distinguish between "impacts" - e.g., the economic loss due to depredating livestock - and "conflict", which was a social debate and conflict among stakeholders over ways to manage impacting species (Redpath et al. 2013). Mitigating and preventing the impact were expected to prevent and reduce conflict, for the conservation of wildlife and the well-being of people. This assumption admittedly did not account for negative attitudes some humans had toward some wildlife species independently from any impact they might generate (large carnivores are a particular example). Emphasizing the role of culture and social learning in complex social animals might enhance attitudes toward these species. The inclusion of social behaviour and social structure and complexity would enhance our appreciation of biologically-sound ways to enhance impact-mitigation, hence more properly informing the socially-based decision-making process to solve and reduce conflict.

Experience among group members highlighted the importance of a participatory approach among all stakeholders and that it was crucial that researchers shared information with 
stakeholders in plain, accessible language. Managing stakeholder expectations was crucial in the process, especially to improve understanding that coexistence situations rarely "resolve" but evolve and require monitoring effort and a toolbox of options for mitigation (see also Recommendation 2). Experience in East Africa (Kenya; elephants and lions) suggested that early discussions and feedback increased a sense of ownership and improved communication between stakeholders, facilitating evolving agreements, as well as containing the spread of unwanted behaviour (crop raiding, livestock depredation) by addressing vulnerability (farm defence, herding practices).

\section{Specific recommendations:}

a) Develop a suite of case studies to explain why taking account of social complexity and animal culture is important and has value for coexistence planning, including the development of site-specific examples for circumstances where HWC occurs.

b) Recognize that human traditional and local knowledge are important aspects of situation-specific human-wildlife interactions at multiple levels and should be considered in developing conservation strategies (Williams \& Whiting 2016).

\section{Recommendation 2. Utilize animal (and human) social learning to facilitate better conservation outcomes in HWC.}

To address HWC, researchers might benefit by starting with an examination of the underlying causes, which might be ecological (such as a temporary food limitation or range expansion into human-dominated landscapes) or anthropogenic, e.g. a change in human activity pattern. The group also discussed the idea that HWC occurred when either the humans or the animals did not "know the rules" when sharing space and resources with other species, which might occur because of changing circumstances (e.g. elephants moving back into former range post-poaching, sharing space with inexperienced human neighbours). Experience showed that researchers needed to have a toolbox of options, rather than relying on single options for dealing with HWC because smart, social animals would continually learn and adapt to human mitigation measures.

If conservation efforts were successful enough, protected wildlife species would increasingly tend to expand into human-dominated urban, suburban and agricultural or pastoral areas. This introduced the idea of conservation planning at the landscape scale, where the likelihood of frequent and recurrent impacts would be expected and where changes in human attitudes/practices were unlikely. Creating a "landscape of coexistence" (Oriol-Cotterill et al. 2015) entailed defining zones at the landscape scale where conservation goals could favour animal species to improve their conservation status (i.e., accounting for social integrity and complexity) in certain zones, while in other areas priority was given to human activities.

The group noted that mitigation measures would work only if the interested parties (e.g. fishermen, ranchers, farmers) were willing to adopt them fully. This related to the functional distinction between impact and conflict. Main affected stakeholders should become part of the solution and their acceptance of the mitigation measures was an essential component of HWC mitigation. Even where human commercial activity was prioritized, management should integrate animal culture and social complexity into the assessment of interventions in the short, medium and long term.

\section{Specific recommendations include:}

a) View HWC as a "cultural arms race" in which both animals and humans are engaged over the long-term;

b) Develop a toolbox of mitigation measures. Mitigation measures may work only in the short-term but must run long enough to enable the spread of learning. The 
success of mitigation strategies may be underestimated if efforts stop too early e.g. migrating elephant populations take longer to learn about beehive fences, because not all population members are immediately exposed;

c) Adopt a pro-active approach. Utilize understanding and the shape of social learning curves (e.g., Roger's innovation curve; Rogers 1962) to target mitigation measures at the early stages during the "window of opportunity" in which only a few individuals are involved (Figure 1);

d) Develop ways to avoid spatio-temporal overlap. The best mitigation measures are likely to be ones that reduce the opportunity for social learning to occur in animals. For example, land-use planning in Kenya is designed to separate incompatible wildlife and agricultural zones; in fisheries, traps or aprons can prevent sperm whale depredation (Arangio 2012); and avoiding the disposal of cattle carcasses near ranches can prevent food conditioning in wolves (Western Wildlife Outreach 2014).

e) Review and assess the efficacy of lethal control measures as applied to highly social species. Culling can affect social network stability and information transfer via social learning opportunities. Destabilising results of culling include elephant behavioural responses (Slotow et al. 2000), disease transmission in badgers (bovine TB; Bielby et al. 2014) and attempts to control wolf populations to reduce livestock depredation or allow recovery of large herbivore populations for hunting purposes.

\section{Recommendation 3. Move beyond counting numbers when assessing the conservation status of highly social species and the outcomes of conservation actions.}

For highly social species, the group emphasized the need to move beyond simply counting individuals when assessing conservation status or the efficacy of management interventions meant to reduce HWC. Rather, we needed simple and practical metrics that enabled us to assess whether a population's social structure was intact and functioning, thereby ensuring social learning and endurance of cultural adaption through generations. We needed to explicitly incorporate sociality into traditional demographic approaches, such as population viability analyses and population dynamic models. We also suggested re-thinking conservation concepts, such as "recovery" when it came to highly social animals, so that conservation practitioners would ask themselves questions such as "what are we trying to recover in these populations"? (age structure? social units? cultural diversity?) and "how would we know when we have achieved these goals"?

\section{Specific recommendations include:}

a) Develop "social indices" for assessing the conservation status of highly social species, designed to measure social structure. Such indices should be situationspecific, might be based on existing metrics, and ideally based on data that are simple to collect. The approach could include representing estimates of the presence/absence of recognizable social units, (such as the presence of matriarchs or dominant males); the age of adult females/males; social group size (e.g., pack size, social stability and site fidelity in social, territorial carnivores such as wolves); or some aspect of foraging or mating system (such as the degree of sexual dimorphism or number of reproductive males [see explanation in Group D]). The group agreed that developing such as measure was beyond the scope of the current workshop but should be considered for future workshops.

b) Investigate new and existing analytical methods for assessing the influence of sublethal impacts on animal sociality and culture, on vital rates and population-level demographics (done in parallel with point (a). See also Group D).

c) Investigate "lag to recovery" across multiple taxa and assess whether attributes such as "highly social" correlate with differences in time to recovery (as demonstrated for cetaceans by Wade et al. 2012). 
d) Examine the opportunity to borrow principles from the ecological literature that describe concepts such as potential persistence and vulnerability of highly social species.

e) Review the functional association between social learning and social complexity in highly social species and their ecological role, where social complexity affects conservation outcomes beyond the single population/species level i.e., ecosystem functioning and services (e.g., trophic cascades of apex predators; such as those described for wolves in Yellowstone, USA, (Ripple et al. 2014; Fortin et al. 2005) (but subsequently contested and counter-contested; East et al. 2017; Beschta \& Ripple 2018).

f)

Table 1. Examples of collisions between human and animal interests and their potential consequences. See text for additional details.

\begin{tabular}{|c|c|c|c|}
\hline Human-wildlife conflict & $\begin{array}{l}\text { Impacts on social } \\
\text { structure }\end{array}$ & $\begin{array}{l}\text { Climate } \\
\text { change impact } \\
\text { on social } \\
\text { learning, } \\
\text { sociality }\end{array}$ & $\begin{array}{l}\text { Human } \\
\text { understanding of } \\
\text { animal culture and } \\
\text { sociality }\end{array}$ \\
\hline $\begin{array}{l}\text { Socially learned predation } \\
\text { ("depredation") by whales, } \\
\text { dolphins, and pinnipeds } \\
\text { on fisheries and by } \\
\text { terrestrial carnivores (e.g., } \\
\text { tigers, lions, wolves, and } \\
\text { bears) on livestock and } \\
\text { domestic animals (e.g., } \\
\text { pets) } \\
\text { Socially transmitted } \\
\text { fence-breaking and crop } \\
\text { raiding by elephants } \\
\text { Socially transmitted } \\
\text { behaviour in which large } \\
\text { carnivores attack humans } \\
\text { and/or damage human } \\
\text { property e.g. beehives, } \\
\text { crops, fruit tree raids by } \\
\text { bears }\end{array}$ & 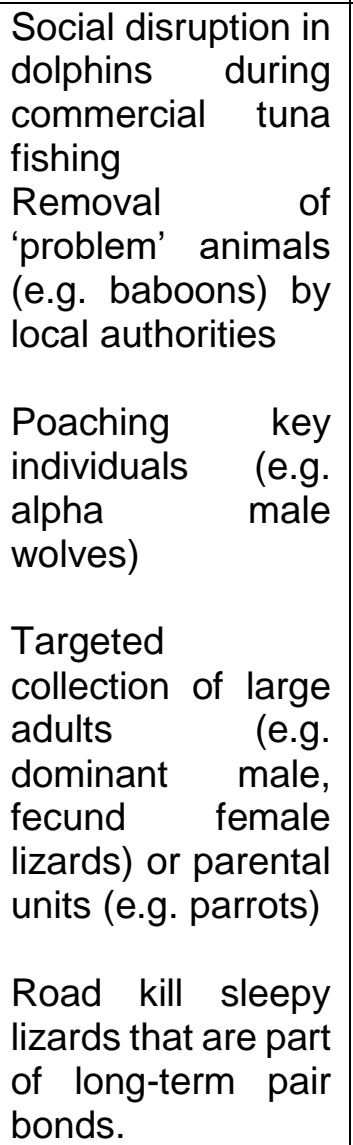 & $\begin{array}{l}\text { Reptiles, } \\
\text { particularly } \\
\text { lizards: } \\
\text { restricted daily } \\
\text { activity for } \\
\text { social learning }\end{array}$ & $\begin{array}{l}\text { Lethal control of } \\
\text { wolves results in } \\
\text { pack instability, } \\
\text { increases number of } \\
\text { breeding pairs, } \\
\text { increasing } \\
\text { depredation } \\
\text { livestock on } \\
\text { Culling elephants } \\
\text { disrupts age-related } \\
\text { learning and social } \\
\text { status, generating } \\
\text { abnormal } \\
\text { (aggressive) } \\
\text { behaviour profiles }\end{array}$ \\
\hline
\end{tabular}




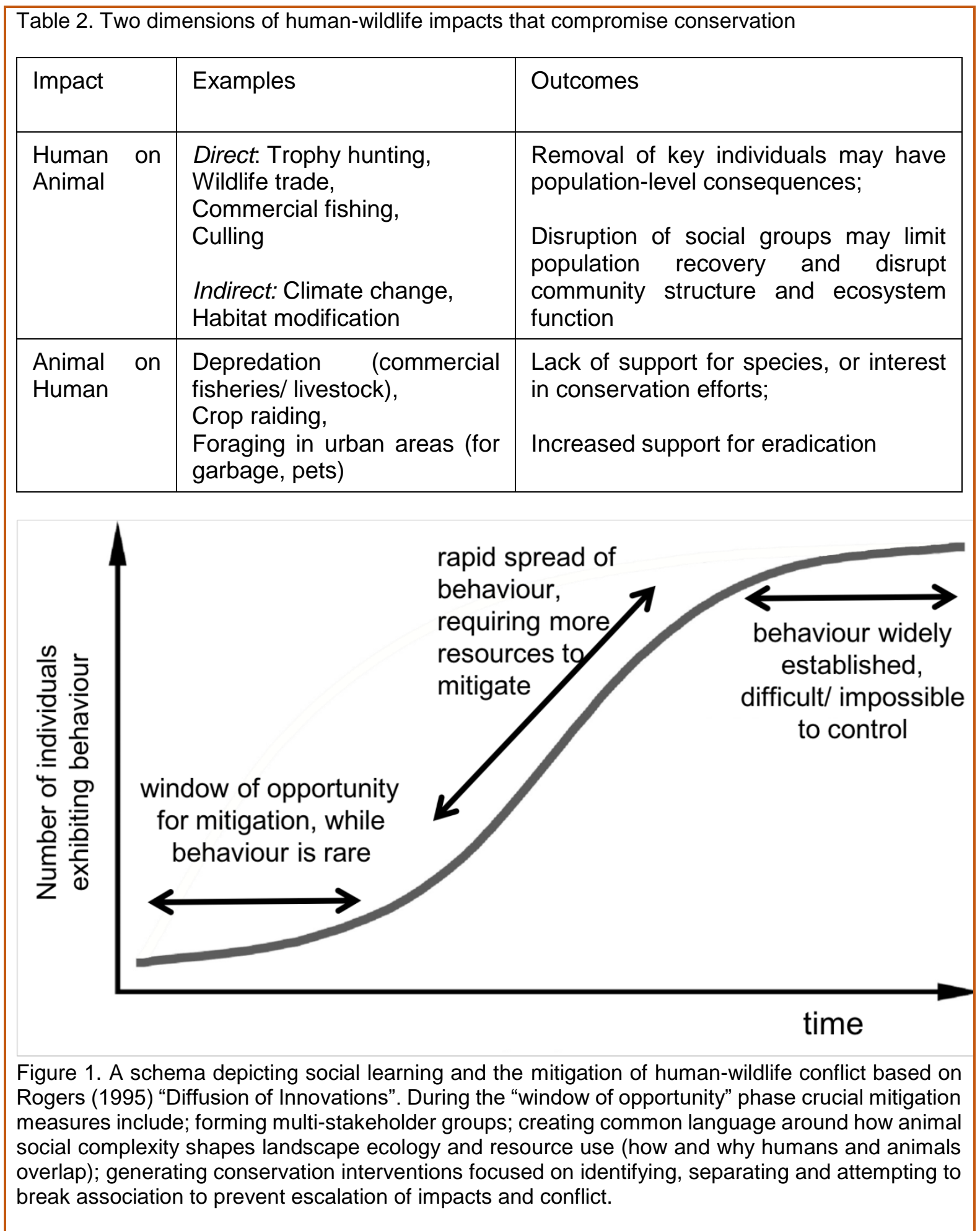




\section{GROUP B \\ 'Wildlife sages': Conserving valuable cultural diversity in wildlife}

Particular concentrations of important cultural information may occur at several levels within a species. Important information or behaviours may reside in, or be used by, particular individuals within a group, in classes of individuals (such as matriarchs), or in whole groups, communities or populations, and yet be absent in other individuals or regional subsets of the species' range. A distinction may be made between efforts directed at the conservation of particular cultural repositories themselves, such as a community that displays a unique behavioural profile transmitted culturally, or at the conservation of critical cultural capacities in the population of interest. Reintroduction projects that relied on humans acting as temporary repositories of cultural phenomena that had gone extinct in the wild, and were then incorporated into the reintroduction process, could be considered a further major type of conservation approach dependent on the recognition of cultural processes in the animals concerned.

\section{Conserving cultural repositories}

Historically, the overarching goal of conservation efforts had been framed predominantly in terms of preserving 'biodiversity', conceptualized in genetic terms. The discovery of widespread animal culture - a 'second inheritance system' (Whiten 2005) that had significant survival consequences - argued to expand this core concept to include phenotypic diversity, with a potentially key component being cultural diversity. Accordingly, a case could be made for conserving a unit that was defined by its cultural identity, rather than purely by its genetic identity.

As one of two illustrative test-cases, we considered the example of nut-cracking using natural hammer materials (wood, stone) in wild Chimpanzees. This behaviour had been documented at eight different research sites that spanned over $500 \mathrm{~km}$ of the range of Pan troglodytes verus in West Africa, but was known not to occur over most of the remainder of Chimpanzees' range in Central and East Africa, including the range of $P$. $t$. verus to the east of the Sassandra N'Zo River (figure 2). Multiple sources of observational and experimental evidence demonstrated that nut-cracking was dependent on cultural transmission from existing experts, but only in this western Chimpanzee population (Whiten 2017a); nutcracking was thus a particularly distinctive and well-documented case among the multiple putative traditions now reported to exist amongst great apes (39 among Chimpanzees, and over 30 and over 20 in Orangutans and Gorillas respectively; Whiten et al. 1999; van Schaik et al. 2003; Krutzen et al. 2011; Robbins et al. 2016). 


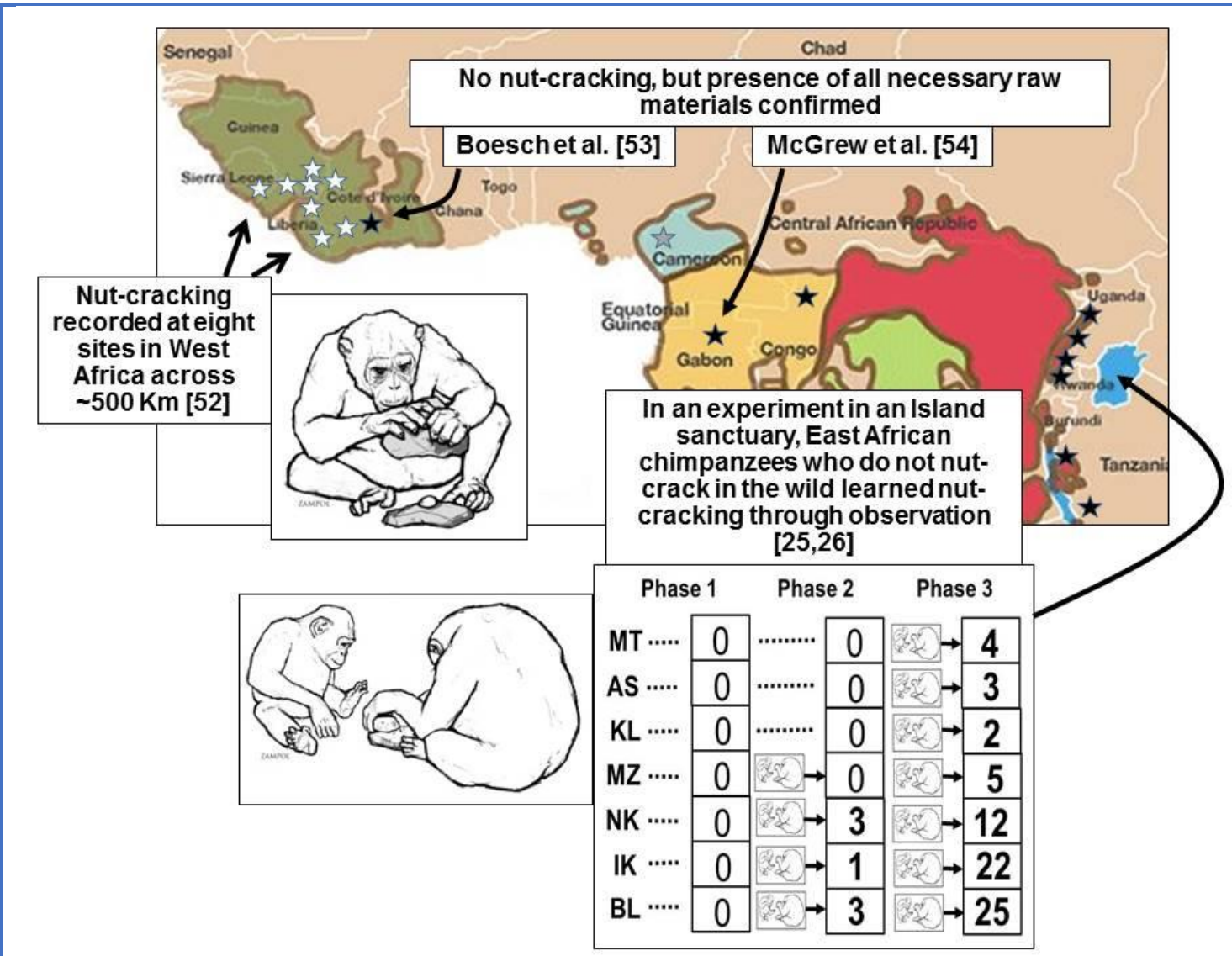

Figure 2. Nut-cracking by Chimpanzees using natural hammer stones and wood has been recorded at multiple study sites in West Africa (white stars) but is known to be absent elsewhere across the species' range, including locations where the availability of all raw materials has been confirmed. Multiple forms of evidence establish nut-cracking as culturally transmitted, including experiments with seven juvenile East African chimpanzees in the Ngamba island sanctuary in Lake Victoria, which initially showed no nut-cracking (phase 1) but when exposed to nut-cracking by an older individual, began to develop the skill (phases 2 and 3) (After Whiten 2017a, b).

Given the critically endangered status of Chimpanzees and that the nut-cracking culture spanned the borders of the four adjacent States of Guinea, Sierra Leone, Liberia and Côte d'Ivoire, the nut-cracking cultural population could be proposed to merit special conservation status on the basis of the following considerations:

(i) Fitness: There was evidence that nut-cracking, along with other forms of tool use, was essential to survival through the dry season when fruit was scarce, and hence chimpanzees' persistence in this western-most portion of their habitat (Yamakoshi 1998).

(ii) Scientific interest: These phenomena importantly extended our understanding of animal ecology and evolutionary biology underling conservation considerations (Whiten 2017b).

(iii) Public interest and investment in conservation: The existence of such cultural phenomena in other species was of great interest to the public, with well-recognized effects on the public's willingness to donate funds to related conservation efforts.

(iv) Relevance to Human Evolution: The percussive technology involved was of high scientific importance given the three-million-years-plus phase of the stone age in our own hominin evolutionary history (Whiten, Schick and Toth 2014; Whiten 2015). 
An ambitious study, 'The Pan African Programme: the Cultured Chimpanzee' of the Max Planck Institute for Evolutionary Anthropology, was underway using camera traps, quantification of resource availability, and other rapid assessment techniques to survey further behavioural diversity amongst chimpanzees across 40 African study sites, and had already revealed forms of behaviour previously unknown (Vaidyanathan 2011, Kuhl et al. 2016).

A second test-case referred to Killer Whales, in which different communities had developed very different hunting specializations, with some feeding specifically on various groups of other marine mammals while others fed exclusively on fish and even penguins. Killer Whales displayed a strong matrilineal social structure with tight family groups, and these dietary preferences appeared to be culturally transmitted from older individuals within each group, as did their songs and migration dispositions. These cultural differences between populations were further illustrated by distinct differences in vocalizations among groups (Ford et al., 2000). These different cultural traits distinguished a number of isolated groups or 'ecotypes' (Ford et al., 2000; Pitman and Ensor, 2003; Riesch et al., 2012), each essentially a cultural repository for specializations in foraging and other behaviours. While currently recognized as a single species (Orcinus orca), there was genetic and morphological support for at least some ecotypes being different species (Morin et al., 2010). To conserve the full biodiversity of these whales it could now be seen to be necessary to recognize and preserve the diversity of these ecotypes.

As in the chimpanzees, there were multiple justifications for measures to conserve such cultural groups:

(i) Fitness: While strong specialization within ecotypes could make some groups more vulnerable to declines in relevant prey species, it could more generally support the resilience of these whales, allowing potentially rapid exploitation and expansion as the availability of suitable prey items fluctuated.

(ii) Ecology: As apex predators, Killer Whale ecotypes had important ecological roles within their specialized niches.

(iii) Public interest: Killer Whales had a high public profile and there was a great deal of public interest in preserving specific cultural groups, such as the resident groups of British Columbia/ Washington.

(iv) Relevance to human evolution: Studying the very strong cultural patterning of this species provided insights into the evolution of human culture as well as animal culture more generally, particularly the role of culture as a potential reproductive isolation mechanism.

\section{Specific Recommendations}

Cultural units should now be considered as units meriting conservation efforts, contrasting with the traditional focus on species, and on genetics. The working group offered the two cases above as 'proofs of concept' for this proposal.

These considerations began to suggest criteria that mighty be used to consider conservation strategies in further significant and culturally defined units, requiring the assembly of information including the following. 
Table 3. Potential variables relevant to conservation of culturally defined units/populations

\begin{tabular}{|l|l|l|l|l|l|l|}
\hline & $\begin{array}{l}\text { CMS } \\
\text { Listing }\end{array}$ & $\begin{array}{l}\text { cross- } \\
\text { border? }\end{array}$ & $\begin{array}{l}\text { fitness } \\
\text { consequence } \\
\text { s }\end{array}$ & $\begin{array}{l}\text { ecological } \\
\text { significanc } \\
\text { e }\end{array}$ & $\begin{array}{l}\text { Public } \\
\text { interes } \\
\text { t }\end{array}$ & $\begin{array}{l}\text { Relevanc } \\
\text { e to } \\
\text { human } \\
\text { evolution }\end{array}$ \\
\hline $\begin{array}{l}\text { P.t.veru } \\
\text { s }\end{array}$ & $\begin{array}{l}\text { Appendi } \\
\text { x I \& II }\end{array}$ & 4 countries & $\begin{array}{l}\text { Survival } \\
\text { through } \\
\text { seasonal } \\
\text { bottlenecks }\end{array}$ & high & high & $\begin{array}{l}\text { percussive } \\
\text { technology } \\
\text { cultural } \\
\text { diversity }\end{array}$ \\
\hline O. orca & $\begin{array}{l}\text { Appendi } \\
\text { x II }\end{array}$ & $\begin{array}{l}\text { multiple } \\
\text { coastal } \\
\text { jurisdiction } \\
\text { s }\end{array}$ & $\begin{array}{l}\text { population } \\
\text { resilience }\end{array}$ & high & high & $\begin{array}{l}\text { cultural } \\
\text { diversity }\end{array}$ \\
\hline $\begin{array}{l}\text { others } \\
\text {... }\end{array}$ & & & & & & \\
\hline
\end{tabular}

\section{Conserving cultural capacities}

Cultural knowledge can form a significant source of locally adaptive behaviour, improving the ability of individuals to survive and populations to persist in the face of human-induced and/or rapid environmental change.

This could potentially be through three main mechanisms. First, cultural knowledge could act as an 'ecological buffer', allowing animals to creatively exploit environments in periods of scarcity. Evidence included comparative analyses in birds, for example, suggesting that a propensity for cognition and social learning could act to expand the range of environments that species could successfully inhabit (Sol et al. 1995). Second, in spatially variable environments, culture could play an important role, acting to 'fine-tune' behaviour to local conditions, and even potentially provide 'resident knowledge' that more transient individuals/species could exploit (Slagsvold \& Wiebe 2007; Seppanen 2007). Third, innovations in response to novel challenges and opportunities could spread via social learning through social networks to establish new cultural behaviours, providing a mechanism by which some species could exploit new beneficial resources (Aplin et al. 2015). In one of the most famous early examples of the spread of innovations, tits (Parus major, Cyanistes caeruleus) learnt to open milk-bottles to eat cream in urban areas, a behaviour that subsequently spread across Britain and Ireland (Fisher \& Hinde 1949).

Many environments were now changing under anthropogenic influences too rapidly for genetic evolutionary processes to keep track, and these cultural processes could be an important way in which species could show resilience. However, to facilitate these processes, it could be important to 'future-proof' populations to conserve the capacity for innovation and social learning, to give rise to new adaptive cultures. This relied on preserving three building blocks of cultural capacity - demography and phenotypic variation, social network structure, and population connectivity.

\section{1) Demography}

Preserving the phenotypic variation in the population was vital both in preserving existing cultural knowledge and for providing the capacity for new cultural behaviours to arise in future. In practice, this would often consist of preserving the social structure of groups (i.e. not disrupting dominance hierarchies), and maintaining age structure in populations. Older and more dominant individuals might be repositories of knowledge (Greggor et al. 2016). 
For example, in Whooping Cranes, the migration routes of juveniles were more efficient when they migrated with older individuals, and the benefits to juveniles improved with increasing age of the adults they flocked with (Mueller et al. 2013). This need to preserve the older individuals in the population might represent a need for a shift in our thinking on hunting and fishing, e.g. trophy-hunting practices, as taking large/older individuals might result in a disproportionate loss of cultural knowledge in the population. Evidence for this effect came from studies in ocean fisheries, where over-harvesting of large/old individuals could lead to loss or changes in migration routes (Brown \& Laland 2005; Petitgas et al. 2010).

A further case study for the importance of preserving age structure came from Killer Whales, well known for their strong matrilineal social structure (Ford et al. 2000). Unusually for mammals, females lived well beyond reproductive senescence. This might have value to group survival through the older females acting as repositories of knowledge about foraging areas and strategies that might be important during times of environmental perturbation. The preservation of older females in Killer Whale family groups might therefore be important to preserve cultural capacities within the group and enhance group fitness.

However, in addition to these considerations, in many species the evidence suggested that juvenile and low-ranking individuals might be the most innovative and exploratory (Perry et al., 2017). Accordingly, they might represent an important source of new adaptive information in populations. This contrast in the different potential roles played by juveniles and adults highlighted the need to maintain the entire age structure of populations, rather than focusing on harvesting or conserving one particular age class.

\section{2) Social network structure}

Information was transmitted through animals' social network ties (Aplin et al. 2015; Hobaiter et al. 2014). Therefore, to maximize cultural capacity in populations, social structure and social connectivity needed to be maintained. The assessment of these social network structures needed to be species-specific. In some species, a proxy of group size might be sufficient; while in other species social network structure might be better assessed monitoring variation in social associations or social connections between groups.

In general, innovative behaviours would be more likely to spread in species with highly fission-fusion based social systems, and possibly in more "egalitarian" societies, where dominance hierarchies were not steep. More specifically, in many species, some classes of individuals connected otherwise disparate groups (e.g. dispersing juveniles, transient individuals). In these cases, preserving such "social brokers" (Lusseau \& Newman 2004) might be particularly important to prevent the social fragmentation of populations.

\section{3) Population connectivity}

Maintaining healthy populations across the entire range of the species might be vital in preserving locally adaptive cultures. For example, individuals in one local area might have a 'resident expertise' or display 'local traditions' not possessed by the entire population, and if this sub-population was lost, then the rest of the population mighty be slow to recolonize this part of the historical range. For example, heavily depleted fish stocks often established different migration routes after recovery (Petitgas et al. 2010), and Right Whales had been slow to re-establish migration paths following whaling, for example in New Zealand (Carroll et al. 2014).

Resident knowledge could also be transmitted between species, with some species acting as "information sources" for a variety of other species or communities. If these "information 
source" species could be identified, they might be a particularly important focus for conservation efforts. For example, Marsh Tits and Willow Tits (Poecile spp.) could give recruitment calls when they found new food patches, attracting other species to patchy ephemeral food sources. They thus acted as 'keystone species' in mixed species foraging flocks (Farine et al. 2015). In another example, experiments using migratory Pied Flycatchers (Ficedula hypoleuca) demonstrated that they used information from resident Great Tits (Parus major) when choosing nest sites (Seppanen 2007).

\section{Specific Recommendations:}

- Consider the overall age and social structure of populations to maintain cultural capacity.

- If particularly important classes of individuals can be identified (e.g. social brokers, matriarchs, individuals with resident knowledge), focus on protecting these individuals and their social connections.

- Where possible maintain population connections across the species' range.

- Identify any important keystone "information source" species within wider species communities, and consider their impact on the conservation of target species.

\section{Reintroducing cultural knowledge}

Reintroductions, in which captive animals were released into the wild in order to re-establish or boost populations, had been widely used as a conservation tool for a range of taxa including fish, amphibians, birds and mammals. However, these schemes had too often had low success rates, largely because they ignored the role of cultural processes in the development of fundamental life skills such as foraging, predator avoidance, social behaviour and nest-site selection (Sarrazin \& Barbault 1996). Re-establishing cultural knowledge had therefore to be a core aim of reintroduction programmes for social animals.

In some cases, where precipitous population declines had caused cultural knowledge to be entirely lost from populations, it might be necessary to use human tutors to promote learning. For example, conservationists had successfully reintroduced migration routes for critically endangered Whooping Cranes by training individuals to follow human microlight pilots (Urbanek et al. 2010; Mueller et al. 2013: Figure 3). In subsequent migrations, these initial trained cranes could then act as effective models for other conspecifics to learn from (Mueller et al. 2013). However, the birds' success in producing surviving offspring had to date been low (Urbanek et al. 2000), probably because the reintroduced birds were handreared and lacked opportunities to learn parental skills from conspecifics. This example illustrated the critical importance of seeking to maintain individuals as repositories of knowledge that might span a number of domains of behaviour, from which others could learn. 


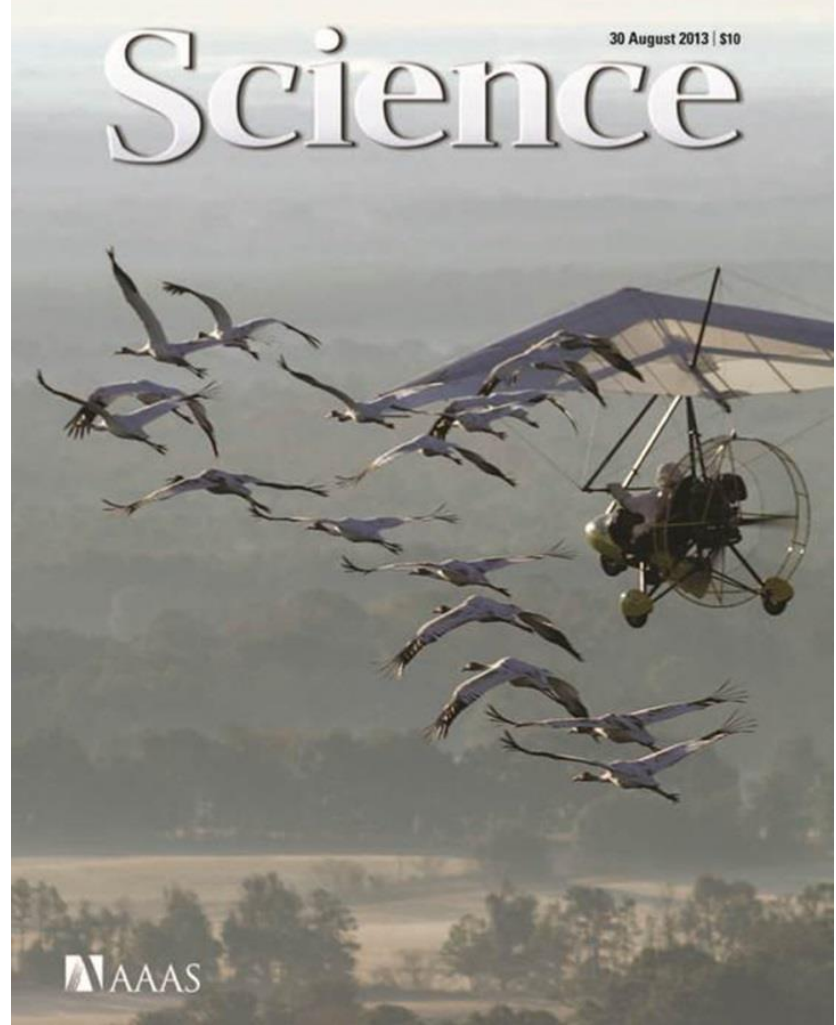

Figure 3. A micro-lite aircraft on which young Whooping Cranes have imprinted is here used to guide the laying down of a migration path these naïve youngsters will learn and follow in future. Here, the micro-lite acts as a surrogate for parents which would normally be the repositories of cultural migratory knowledge passed down through generations (Mueller et al. 2013).

Another relevant example was the case of Golden Lion Tamarins (Leontopithecus rosalia), also critically endangered at the time reintroduction efforts were begun (Beck et al. 2002) Here the survival rates of reintroduced animals were initially extremely low (13\%), as captive-born individuals failed to forage effectively and recognize predators (Stoinski et al. 2003). Later, an intensive post-release programme involving provisioning of supplemental food and nest-sites allowed reintroduced animals to survive for long enough to learn basic life skills, doubling survival rates. The offspring of these captive-born animals then showed a much improved survival rate of $70 \%$, suggesting that social learning from parents made a critical contribution to the acquisition of fitness-related behaviour (Kierulff et al. 2012).

It was concluded that wherever possible, reintroduction schemes should seek to promote the cultural transmission of fitness-related knowledge and skills, by exposing captive-born individuals to experienced conspecifics, both during rearing/rehabilitation and when being released back into the wild. For instance, for flocking birds such as psittacines, soft-release protocols sought to promote social integration post-release by setting up perches and feeding stations to promote aggregation of individuals, both amongst these individuals and then with wild, experienced conspecifics (White et al. 2012), an approach for which there was some evidence of success also from the Golden Lion Tamarin project.

Finally, to evaluate and improve success rates for reintroductions, we recommended that all schemes kept systematic, detailed records of data on individuals' social interactions and exposure to relevant stimuli (e.g. different food types; predators) both pre- and post-release, as well as their subsequent survival and reproductive success. Attention should also be given to the possibility that behaviour patterns resulting from a phase of captivity, such as loss of fear of humans, did not have negative consequences after release into the wild. 
Collaborators from the scientific research community might also be invited to become involved, to benefit from the unique opportunities to learn the impacts of social learning during re-introduction programmes.

\section{Recommendations:}

- Wherever possible, individuals scheduled for re-introduction should be exposed to experienced conspecifics interacting with a range of stimuli they are likely to encounter in the wild (e.g. conspecifics; foods; predators)

- Where cultural knowledge has been entirely lost in the wild, in some circumstances human tutors should be used to re-establish desired behaviour, especially in the first release generation.

- In species that show parental care, intensive support should be provided to support breeding, when future generations are predicted to learn from the most competent surviving conspecific parental models.

- Likely social learning biases should be taken into account; for example, individuals may be more likely to learn from adults, or from resident individuals.

- Staff should monitor and maintain data as detailed as is practicable encompassing individuals' social interactions (e.g. social affiliations; exposure to human or conspecific models) and exposure to stimuli pre- and post-release

\section{GROUP C}

Socio-geography: Social learning, range recovery and migration, island populations

The group members saw socio-geography as the integration of culture and social learning into the broader field of conservation biology, linking the importance of culture and social learning to existing spatial understanding of range dynamics and migration in macroecology and biogeography (e.g., Keith and Bull, 2017). Our taxonomic expertise centred on cetaceans and birds and our discussions covered aspects of behavioural ecology, acoustics, genetics, biologging and biochemical markers. We considered that the three main ways that culture and social learning shape phenotypic diversity, demography and population structure are (1) learning and transmission of behaviours; (2) effective transmission of information through social networks and (3) the promotion of isolation among animal sub-groups. These processes could act as modes of transmission of information that can be long-term (e.g. migratory routes), ephemeral (e.g. foraging patches, song variation), or both. We highlighted that a practical element of this section of the report had been to identify behaviours, environments and systems where social learning (as a potential precursor to more permanent culture) might play an important role including: social foraging; complex foraging tasks; migratory tradition conservatism; vocal learning; fissionfusion or matrilineal-unit-based social systems, long-term parental care; and, in turn, how these might influence/impact conservation status and initiatives.

1. Goal of conservation. The goal of conservation is to maintain the evolutionary potential and long-term persistence of viable populations of wild species: this can include maintaining cultural as well as genetic diversity.

Evolutionary potential includes the potential for changes in functional genes, as well as other processes of inheritance, including social learning. For example, in 1980 a Humpback Whale in the Gulf of Maine invented a new feeding technique. This spread through the social network of the population through horizontal social learning, and was used presumably to enhance foraging efficiency (Allen et al., 2013). Other examples of rare, but possibly functional, behaviour spreading through a population included moss sponging in 
Chimpanzees (Hobaiter et al., 2014); and rapidly growing subpopulation of Barnacle Geese that started breeding in Iceland in the late 1980s, shortening the ancestral migration route by over one thousand kilometres: this new breeding area could act as a buffer for the whole population, the bulk of which bred in Northern Greenland, in the face of changing arctic environments (Stefánsson et al. 2015).

2. Evolutionary potential and long-term persistence. To maintain evolutionary potential and long-term persistence, we need to preserve
a. Phenotypic diversity
b. The demography and population structure of populations that will often contain a spatial component.

3. Culture. Animal culture is a cause (driver), consequence and marker of
a. phenotypic diversity
b. demography
c. population structure

4. Effects of culture. Culture acts through the following processes which can be generally differentiated based on whether the information being transmitted is long-term or ephemeral, or both

a. learning and transmission of migratory routes (long-term)

- The social systems and site fidelity of subpopulations of light-bellied Brent Geese and White-fronted Geese were more similar to one another across a shared migration route, than they were to conspecifics using different migratory flyways (Fox et al., 2002; Ackerman et al., 2006; Harrison et al., 2010).

b. effective transmission of information through animal networks and an understanding of the critical densities at which these networks broke down (ephemeral)

- A modelling study of the effects of social facilitation on vulture foraging success demonstrated that there were critical densities at which information flow broke down and sent a population into rapid decline (Jackson et al., 2008)

c. promotion of isolation of units (both ephemeral and long-term)

- Matrilineal culture and gene-culture coevolution could drive demographic and genetic isolation in some Killer Whale populations and ecotypes, probably facilitating speciation (Riesch et al., 2012; Morin et al., 2015; Foote et al., 2016).

5. Extrinsic factors. Extrinsic factors (anthropogenic or natural) could influence these processes, which in turn could affect both evolutionary potential and long-term population viability:

a. Destroying, degrading or disrupting migratory corridors or destinations;

- There was genetic and stable isotope evidence that Southern Right Whales have maternally-directed learning of breeding and feeding migration habitat. Whaling had extirpated whales from parts of the migration network, with a corresponding loss of cultural memory of migration destinations leading to spatially variable recovery and concerns about population viability (Carroll et al., 2015). This seemed to be a more general effect with other heavily hunted species with presumed culturally-determined migration routes (Clapham et al., 2008), such as Beluga Whales (O'Corry-Crowe et al., 2018).

b. Perturbing the animal network to reduce functional effectiveness of information transfer, including density dependence effects at low densities, resulting from a positive relationship between any component of individual fitness and either 
numbers or density of conspecifics (e.g., the Allee effect; Allee, 1931; Courchamp et al., 1999; Stephens et al. 1999).

- See 4bi (vultures).

c. Removing or reducing viability/integrity of units

- Southern resident Killer Whales were a small ( $<100$ animals), distinct community with a highly specialized, and conservative, cultural behavioural repertoire. Both their habitat and their overwhelmingly-preferred food source (chinook salmon) were being heavily impacted by human activities, leading to substantial risk of extirpation (Lacy et al., 2017).

6. Culture and conservation. Recognizing that culture is another aspect of biology that should be considered within existing conservation initiatives we recommend that culture should be considered in the following contexts:

a. assessing populations and designating units to conserve (e.g. evolutionary significant units)

- Beluga populations in Canada were separated into eight Designatable Units (by the Committee on the Status of Endangered Wildlife in Canada) which had a range of conservation status' from "Endangered" to "Not at Risk" (COSEWIC 2004). COSEWIC assessment and update status report on the Beluga Whale Delphinapterus leucas in Canada. Committee on the Status of Endangered Wildlife in Canada. Ottawa. ix + 70 pp. [Online: www.sararegistry.gc.ca/status/status e.cfm].). Some of these Designatable Units mixed during winter and spring when they mated, but the migrations to discrete summer habitats and behaviour in these habitats seemed to be culturally learned, and these were considered sufficiently distinctive to separate the designatable units.

b. introgression and hybridization

- hybridization and introgression were major threats to the species' persistence and population structure of multiple species including wolves (Adams et al., 2003; Benson et al., 2012; Caniglia et al., 2014) and wild cats (Anile et al., 2014; Steyer et al., 2016). It was possible that socially learned behaviours could be eroded, modified or replaced during such events, or behaviours with a genetic or partially genetic basis could be impacted (Allendorf et al., 2001). Unfortunately, evidence for this was not currently available and as such this should be a target for future research.

c. managing endangered populations: retraining, local enhancement

- Work was underway to preserve a suite of potentially socially-transmitted behaviours in a captive population of the critically endangered Hawaiian Crows which was used to breed birds for an ongoing reintroduction programme (Hoppitt et al. in prep.) (see also sub-group B section 3. Reintroducing cultural knowledge).

- A combination of reintroductions and vulture feeding stations was being implemented to facilitate the reestablishment of the information networks required for social facilitation of foraging (Houston and Piper, 2006). In India this had the added benefit of high-jacking social facilitation to lure vultures away from poisoned carcasses (Gilbert et al., 2007).

- Northern Quolls showed taste aversion to toxic cane toads after training in captivity with a toad sausage (Indigo et al., 2018). A similar approach in situ with varanid lizards using small toads resulted in conditioned taste aversion in advance of the arrival of larger, potentially-lethal introduced toads (WardFear et al., 2016). If such aversions could be transmitted through social learning, as had been shown for some predator avoidance behaviour (Griffin, 2004), these approaches might be especially effective. This was a potential approach for hatchery-reared fish (Brown and Laland, 2001). 
d. mitigation planning for environmental change and development

- Where there was a high level of migratory connectivity and site fidelity, which are often culturally transmitted, it had been argued that individual sites may require particular levels of protection. For example, the high migratory connectivity and extreme site loyalty shown by some geese had led researchers to argue for individual refuge designation (Fox et al., 2002). North Atlantic Right Whales had a migration route, presumably culturally learned, that passed through some highly-used and increasingly-used coastal environments on the east coast of North America. A number of protection measures, such as vessel restrictions, had been introduced at various points in this route (Kraus and Rolland, 2007). However, further research was required to determine whether these sites would become suboptimal under environmental change ('ecological trap'), and the extent to which behavioural flexibility could mitigate this issue.

\section{General recommendations}

a. Collect empirical evidence of social learning network and migratory behaviour and connections

b. Develop theoretical models to inform mitigation and investigate future scenarios, e.g. as done to investigate the link between social transmission of information and viability in vultures (Jackson et al. 2008).

c. Develop rapid assessment tools and emerging technologies to provide direct and indirect evidence of social transmission, migration routes, social networks, as well as anthropogenic effects on behaviour, informing conservation and management

- Acoustics: passive acoustic monitoring; acoustic identification of population units; autonomous recording with identification software (Zimmer, 2011)

- Biologging: movement and activity tracking; direct and indirect encounter mapping for social network building (Krause et al., 2013; Hussey et al., 2015; Kays et al., 2015).

- Genetic and genomic techniques including eDNA and minimally-invasive sampling to identify kin groups, population structure and migratory connections (Arandjelovic and Vigilant, 2018; Carroll et al., 2018)

- Stable isotopes, fatty acids and other biochemical markers to delineate population segments with distinct habitat use, as well as transmission patterns of foraging behaviour

- Proxies of culture that can be assessed more easily. For example, in toolusing New Caledonian Crows, the idea had been explored to rapidly map possible regional variation in foraging behaviour, using vocal dialects as 'markers' (Bluff et al., 2010)

d. As noted in CMS Resolution 11.23: management decisions should be precautionary and assume that populations may contain discrete social elements which have conservation significance warranting further investigation.

- Emerging indications that culture might have a conservation consequence could include: social foraging; complex foraging tasks; migratory tradition conservatism; vocal learning; fission-fusion or matrilineal-unit-based social systems, and long-term parental care 
Figure 4: Schematic depicting how the desired outcome of conservation, the maintenance of longterm viable populations and phenotypic diversity, can be achieved by interventions and recommendations that consider the interrelationship between demography, population structure, extrinsic processes and culture.

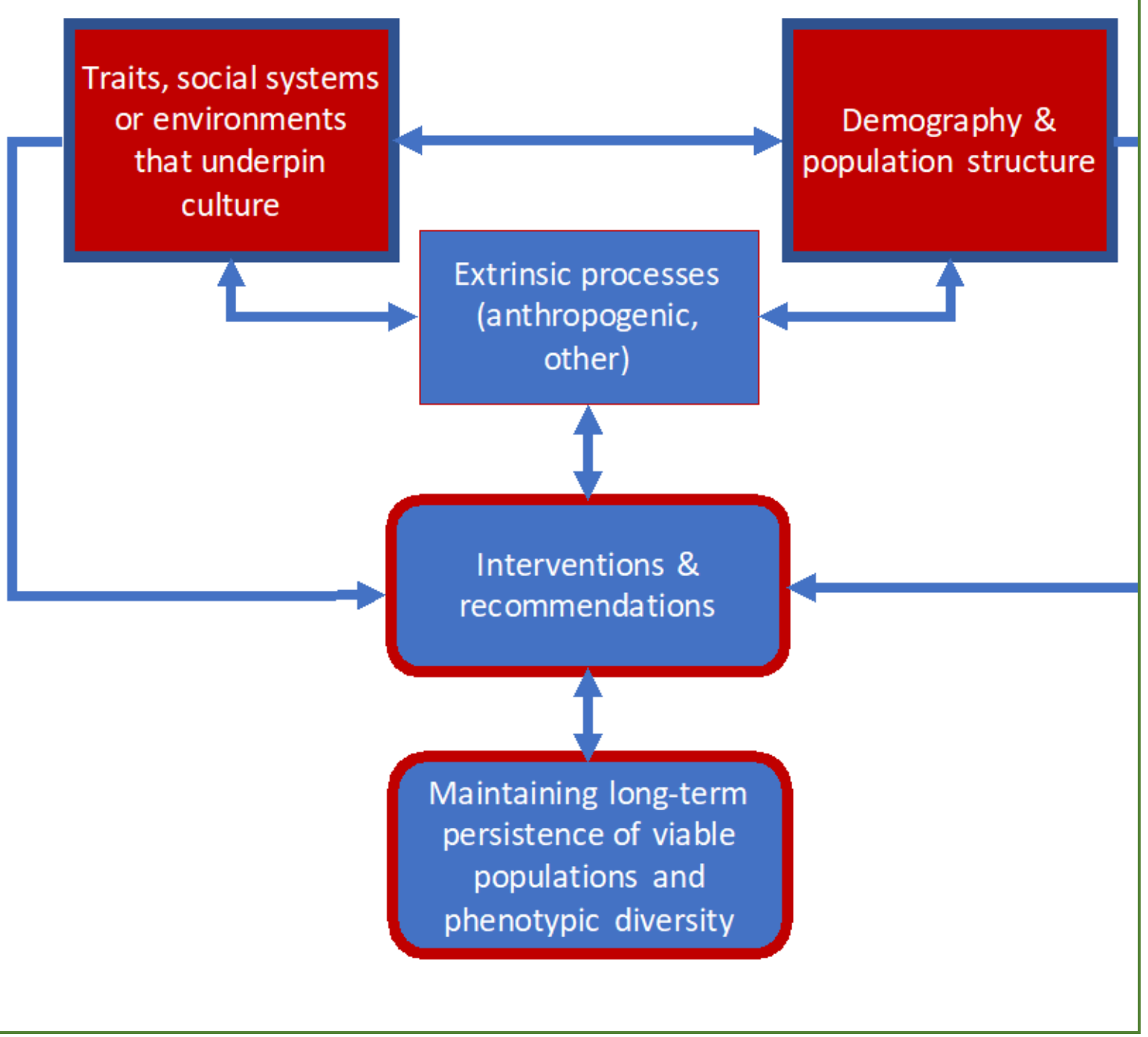




\section{GROUP D \\ Socio-vulnerability: Specialization versus ecological resilience}

\section{Cultural specialization of foraging}

Aspects of social complexity and culture in animal populations can increase the vulnerability of species to anthropogenic and other environmental threats. Below, we describe some of the ways in which social factors can affect conservation risk. We also briefly considered whether it is possible to create a scheme to categorize species vulnerability based on their social complexity or other identifiable aspects of their social systems. However, we concluded that was a task beyond the scope of this workshop and should be explored further at subsequent workshops.

Socially complex species can contain different foraging cultures that require extensive learning of specialised foraging techniques. For example, different social units within fisheating Killer Whales (Orcinus orca) may forage on anadromous fish (e.g. chinook salmon) specific to individual river systems (Ford et al. 2000, Ford and Ellis 2006), and different social units within mammal-eating Killer Whales specialize in hunting either Gray Whales or Harbour Seals (Ford and Ellis 1999).

Foraging specialization amongst whale clans can lead sub-populations to respond differently to environmental change. Members of two Sperm Whale clans studied off the Galapagos showed differential responses to the El Niño phenomenon. During normal cool years, the "Regular" clan had higher feeding success than the "Plus-one" clan. Whereas, in years with warmer El Niño conditions "Plus-one" clan groups were more successful (Whitehead and Rendell, 2004). More recent investigations have shown both of those clans have been replaced in the Galapagos by two different clans (the "Short" and the "Four-plus" clans), with the authors' interpretation being that clans with different foraging strategies relocated when those strategies were no longer efficient, rather than changing their foraging strategy (Cantor et al. 2016). The implication is that some cultural groups may relocate rather than adapt to environmental change.

Prey use also varies in terrestrial mammals. Foraging specialization between social units is also known from species such as wolves and African Wild Dogs, which could feasibly affect their response to environmental change. In Africa, some Chimpanzee communities display learnt tool use, using rocks or sticks to crack open nuts, yet this behaviour is not evident in neighbouring communities that exist within comparable habitat (Whiten, 2015). Bornean Orangutans also display evidence of learning in a cultural context, where social groups separated only by a river barrier have different diets that persist through time, which do not appear to be a direct result of resource availability (Bastian et al., 2010).

Populations of baleen whales (Right Whales, Humpback Whales) congregate in a single location to calve in the winter, yet from that location, individuals migrate to a range of locations to feed and mate. Individual whales tend to return predominantly to the same feeding area for their entire lives, which was the first area experienced for this purpose as a calf (e.g., Carroll et al. 2015; Baker et al. 2013). Similarly, evidence for natal philopatry to migration destinations, apparently parentally directed, is also seen in Belugas, a toothed whale (O'Corry-Crowe et al. 2018). Therefore, feeding areas represent cultural traditions that are vertically transmitted from parent to offspring.

Strong vertical transmission of cultural knowledge is common in socially complex species, potentially rendering individuals of those species incapable of rapidly changing behaviours under novel conditions. Therefore, this highlights a new aspect of vulnerability for these 
species as persistence in the face of environmental or human-induced change is compromised (Keith \& Bull, 2017). For example, if a social unit has invested in learning a specific hunting technique and the target prey species decreases in abundance, it may be extremely costly, both for individuals and for the species as a whole, to change their technique to take advantage of alternative prey. Figure 5 provides a schematic representation of the vulnerability of social groups with different cultural foraging traditions in the face of environmental change, as groups are either stable, adapt or die.

Figure 5.

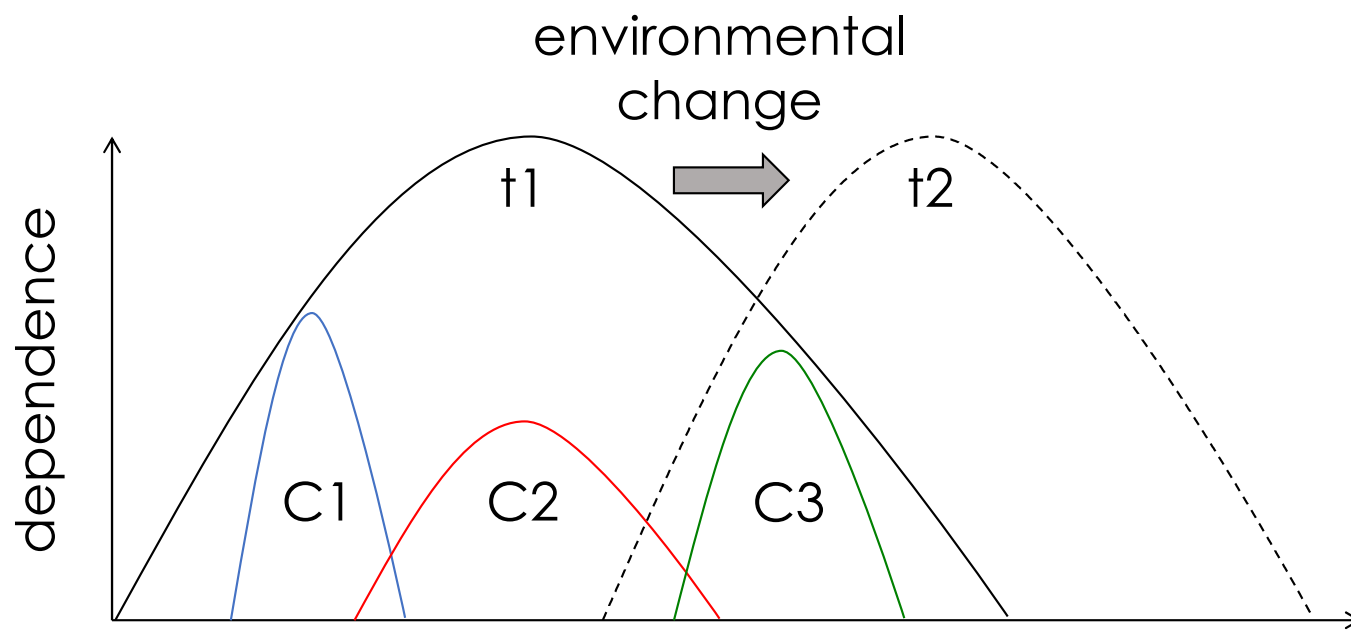

resource

Cultural groups (C1, C2, C3) consume distinct resources due to socially learnt specialization of foraging strategies. Under a scenario of environmental change (e.g., increased temperatures), the resource base can shift over time (from t1 to t2) and create vulnerability dependent on the potential for cultural groups to track exploit new resources. In the example here, environmental change will result in loss of $\mathrm{C} 1$ and persistence of $\mathrm{C} 3$, whilst the persistence of $\mathrm{C} 2$ will depend on its capacity to forage for resources that are currently consumed with low probability.

RECOMMENDATION: Recognize that species with multiple foraging cultures have multiple resource requirements that are not clear from observations of a single cultural group. Failure to recognize and protect these multiple resource requirements could exacerbate existing conservation issues.

\section{Vulnerability resulting from other aspects of sociality}

Mating systems are another aspect of sociality that could alter vulnerability of some species. Removal of key individuals in systems that depend on a strict hierarchy for mating "rights" could be detrimental to an entire group or population. For example, in species with strong sexual dimorphism, which implies strong sexual selection, removal of key breeding males can substantially reduce fecundity even though many males remain in the population. Conversely, reductions in nomadic male lions can increase local populations due to reduced infanticide (Borrego et al 2018). Therefore, individuals are not equal. Rather, removal of individuals can scale up to impact the population through a variety of mechanisms, which could have consequences beyond predictions that assume individuals are equivalent, as 
many conservation targets are based upon (see Table 4 for examples from odontocete cetaceans).

Table 4. An example of possible mechanisms in social odontocetes where direct removals from a population can have a greater effect on population dynamics than predicted by population models with individual equivalence (adapted from Wade et al., 2012).

\begin{tabular}{|l|}
\hline a. Mechanisms for which there is some evidence \\
\hline Deficit of reproductive-age females (killer whales) \\
\hline Deficit of adult males leading to lower pregnancy rate in females (sperm whales) \\
\hline $\begin{array}{l}\text { Lowered birth rate from disruption of mating systems (spinner and pantropical spotted } \\
\text { dolphins) }\end{array}$ \\
\hline $\begin{array}{l}\text { Physical separation of cow/calf pairs from chase and harassment leading to death of } \\
\text { calves (spinner and spotted dolphins) }\end{array}$ \\
\hline
\end{tabular}

b. Additional mechanisms suggested by the species' social systems

Loss of cultural knowledge concerning, e.g., types of alternative prey, areas where prey can be found, and ways to capture different types of prey under varying circumstances (Killer Whales, Sperm Whales, Belugas, Narwhals, Pilot Whales)

Increased risk of ice entrapment due to loss of cultural knowledge (belugas, narwhals)

Disruption of social networks by removal of key individuals leading to dispersal and potentially higher mortality rates (Bottlenose Dolphins, Killer Whales)

Loss of an important non-reproductive role by older females (Pilot Whales, Killer Whales, Sperm Whales)

Increased predation risk due to loss of social connection and "babysitting" by nonrelatives (Sperm Whales)

RECOMMENDATION: Design a scheme to categorise species vulnerability based on recognizable aspects of their social structure, such as mating systems (e.g., Lang et al 2017 on social predation strategies). Such a scheme was beyond the scope of this workshop.

Another aspect of sociality and culture is recognition that a species may have habitat requirements in addition to prey resources. For example, in species that use designated aggregation areas, or "leks", for breeding (e.g., Black Grouse, fruit bats, paper wasps), the specific location can develop over time as a tradition. If the lekking area undergoes anthropogenic disruption, this could reduce the fecundity of the population until a new tradition can be developed. In some reef fishes, such as Blue-headed Wrasse, "breeding arenas" appear to be socially determined and culturally transmitted (Warner 1988). When resource bases within the arenas were altered, the fish continued to use the same area. However, when fish populations were transplanted between reefs they established new breeding arenas completely distinct from previous "native" populations. Other non-breeding locations are similarly constrained by culture. Communal use of some roosts by bats and birds (e.g. ravens) appear to be based on tradition, rather than tied to a specific resource. In other words, the locations might be somewhat arbitrary (many suitable locations may exist), but once a location is chosen the colony stays faithful to that location.

Cultural constraints can also be important for non-food resources used by some socially complex populations. For example, some Killer Whale populations use rubbing beaches, presumably to exfoliate skin, which are not shared by other sympatric populations (Ford et al. 2000). Habitat use with the presumed aim to avoid humans is seen in wolves and bears in Europe, where individuals have learned which locations in human-modified landscapes areas are safe from hunting or lethal defence of livestock (Ciucci et al. 2018). 
RECOMMENDATION: Consider the location of non-food resources (e.g., breeding, health maintenance, human avoidance) for understanding and protecting habitat needs of socially complex species.

However, it should not be assumed that any culturally determined foraging specialization is inflexible and leads to vulnerability. For example, an experiment on Great Tits (Parus major) showed how an introduced foraging technique can spread rapidly through social networks to become established as a very stable local culture (Aplin et al. 2015). However, in a further experiment that changed the resources again, the tradition was not constrained but rather shifted rapidly to a more optimal technique (Aplin et al. 2017). Both of these outcomes were considered to be facilitated by the fission-fusion social system and rapid horizontal learning observed in this species. It is therefore possible that how cultural information is transmitted may determine how open it is to change. For instance, vertically transmitted foraging techniques may confer less flexibility and greater vulnerability to ecological change in comparison with horizontally transmitted (within generation) habitat choices that can be refined by individual experience (Keith \& Bull, 2017).

RECOMMENDATION: Initiate research to determine if the mechanism of cultural transmission of information can be used as a proxy to categorize species vulnerability.

\section{Identification of priority CMS-listed species or populations which may benefit from concerted action}

In a discussion facilitated by Giuseppe Notarbartolo di Sciara, the CMS COP-appointed Councillor for Aquatic Mammals, it was agreed that there are a number of characteristics of the species on the CMS appendices which could be used to prioritize action within the list and also, potentially identify further species for which may also benefit from listing on the appendices.

It was noted that the taxa currently listed on the CMS appendices are likely to only represent a subset of species that exhibit social learning and cultural traditions in their migratory behaviour and movement patterns. When identifying potential candidates for listing on the appendices and also when identifying species within the list where social learning is of relevance and import to conservation initiates, it was recommended that any one or more of the following characteristics be considered:

- species with extended parental care

- species that forage in social groups

- species that exhibit complex foraging skills

- species that use social information to make foraging/movement decisions, particularly those exhibiting fission-fusion dynamics

- species that migrate in social groups

Examples might include, but not be restricted to, species that move in kin-based units (e.g. some felids, some canids, some lizards, some primates, some odontocetes, cooperative breeding species); stable non-kin based social units (e.g. some primates); colonial roosting/breeding bats and birds (e.g. seabirds); species that aggregate at food sources or at migratory stop over sites (e.g. vultures; geese). 


\section{E. Explore opportunities for synergies with other CMS agreements and initiatives}

The relevance of culture and social complexity for conservation to CMS daughter agreements was discussed. Through this process, it has been recognised that social learning, culture and other aspects of sociality may be important when planning actions for the conservation of migratory species. Through this workshop and the existing expert group and via the development of collaboration between experts steered by the Parma workshop, CMS now has a new tool to support conservation activities planned by daughter agreements within the CMS family for species where there is evidence of aspects of sociality of relevance to conservation efforts.

\section{F. Closing Remarks}

There was agreement that given the fruitful discussions and importance of the subjects of animal culture, social complexity and social learning for conservation efforts, it would be worthwhile pursuing joint publications in peer reviewed journals. More details would be discussed in due course.

A process for finalizing the report of the meeting, including the sub-groups, was agreed, with the aim of having it available by the end of May for information of the $3^{\text {rd }}$ Meeting of the Sessional Committee of the Scientific Council.

The Steering Group for this workshop and participants expressed their thanks to the hosts and sponsors, the Appennino Tosco-Emiliano National Park, the Fondazione Monteparma, and the Principality of Monaco, for the excellent hospitality, which had even included a delightful concert by the Corale Lirica San Rocco. Participants also thanked the Steering Group for the substantive preparations and excellent facilitation, and the Secretariat. 


\section{ANNEX 1: Agenda}
A. Opening and Introductions
B. Background Presentations

1. CMS background

1.1. History, context and mandates for the workshop

1.2. CMS Scientific Council, species appendices and progress to date

2. Social learning and conservation across taxa: definitions, methods and relevance

C. Conservation Priorities for CMS-listed Species

Sub-group discussions:

- Worlds that collide: Human-wildlife conflict (HWC) and anthropo-dependence

- Wildlife sages: Conserving valuable cultural diversity in wildlife

- Socio-geography: Social learning, range recovery and migration, island populations

- Socio-vulnerability: Specialization versus ecological resilience

D. Identification of priority CMS listed species or populations which may benefit from concerted action

E. Explore opportunities for synergies with other CMS agreements and initiatives

F. Closing Remarks 


\section{ANNEX 2: List of Participants}

\section{Invited Experts}

Dr Lucy Aplin

Max Planck Institute for Ornithology

Vogelwarte Radolfzell

Am Obstberg 1

Radolfzell 78315

Germany

laplin@orn.mpg.de

Prof Stuart Bearhop

Centre for Ecology \& Conservation

University of Exeter, Penryn Campus

Penryn, Cornwall TR10 9FE

United Kingdom

S.Bearhop@exeter.ac.uk

Tel. +44 1326371835

Dr Emma Carroll

Bute Building

School of Biology

University of St Andrews

St Andrews, Fife, KY16 9TS

United Kingdom

carrollemz@gmail.com

Tel. +44 7482245487

Dr Paolo Ciucci

Dipartimento di Biologia e Biotecnologie

University of Rome La Sapienza

Viale dell'Università 32

00185 Roma

Italy

paolo.ciucci@uniroma1.it

Tel. +39649914950

Dr Sasha Dall

Centre for Ecology \& Conservation

University of Exeter, Penryn Campus

Penryn TR109FE

United Kingdom

s.r.x.dall@exeter.ac.uk

Tel. +441326371860

Dr Vicki Fishlock

Amboseli Trust for Elephants

PO Box 15135

00509, Nairobi

Kenya

vicki.fishlock@gmail.com

Tel. +254 710881768
Dr John Ford

University of British Columbia

5190 Fillinger Crescent

Nanaimo, BC V9V $1 \mathrm{H} 8$

Canada

john.ford@ubc.ca

Tel. +12506674698

Dr Ellen Garland

Sir Harold Mitchell Building

School of Biology

University of St. Andrews

St. Andrews, Fife, KY16 $9^{\mathrm{TH}}$

United Kingdom

ecg5@st-andrews.ac.uk

Tel. +44 7478649964

Dr Sally Keith

Lancaster Environment Centre

Lancaster University

Lancaster, LA1 4YQ

United Kingdom

sally.a.keith@gmail.com

Tel. +447465998884

Dr Peter McGregor

Centre for Applied Zoology

Cornwall College Newquay

Trenance Gardens

Newquay TR7 2LZ

United Kingdom

peter.mcgregor@cornwall.ac.uk

Tel. +447484797632

Dr Sarah Mesnick

NOAA Fisheries

National Oceanic and Atmospheric

Administration

8901 La Jolla Shores Drive

United States

sarah.mesnick@noaa.gov

Tel. +18485467148

Dr Michael Noad

The University of Queensland

42 Delville Ave

Moorooka, Queensland

Australia

mnoad@uq.edu.au

+61416270567 
Dr Martha Robbins

Max Planck Institute for Evolutionary

Anthropology

Deutscher Platz 6

04103 Leipzig, Germany

robbins@eva.mpg.de

Tel. +443413550210

Prof Christian Rutz

School of Biology

University of St Andrews

St Andrews KY16 9 ${ }^{\mathrm{TH}}$

United Kingdom

christian.rutz@st-andrews.ac.uk

Dr James Alexander Thornton

Centre for Ecology and Conservation

University of Exeter, Penryn Campus

TR10 9FE

United Kingdom

alex.thornton@exeter.ac.uk

Tel. +44 1326255081

Dr Paul Wade

NOAA Fisheries

1105 NW 200th St

United States

paul.wade@noaa.gov

Tel. +12069305389
Prof Hal Whitehead

Department of Biology

Dalhousie University

1355 Oxford St.

P.O. Box 15000

Halifax, NS, B3H 4R2

Canada

hwhitehe@dal.ca

Tel. +19024943723

Prof Andrew Whiten

Centre for Social Learning and Cognitive

Evolution

School of Psychology and Neuroscience

University of St Andrews

St Andrews, KY16 9JP

United Kingdom

a.whiten@st-andrews.ac.uk

Tel. +44 1334462073

Prof Martin Whiting

Department of Biological Sciences

Macquarie University

NSW 2109

Australia

martin.whiting@mq.edu.au

Tel. +61402752229

Dr James Williams

CMS Scientific Council

Joint Nature Conservation Committee

Monkstone House, City Road

Peterborough, PE1 1 JYU

United Kingdom

james.williams@incc.gov.uk

+441733866868

Mr Mark Simmonds

University of Bristol

School of Veterinary Sciences

Langford, Bristol BS40 5DU

United Kingdom

mark.simmonds@sciencegyre.co.uk

Tel. +447809643000

Dr Fernando Spina

CMS Scientific Council

ISPRA

Via Ca Fornacetta, 9

I-40064 Ozzano Emilia (BO)

Italy

fernando.spina@isprambiente.it

Tel. +393473507032 


\section{Hosts}

Ms Mia Canestrini

Parco Nazionale dell' Appennino Tosco-

Emiliano

Mr Roberto Delsignore

Presidente

Fondazione Monteparma

Sen. Fausto Giovanelli

Presidente

Parco Nazionale dell' Appennino Tosco-

Emiliano

Mr Giuseppe Vignali

Director

Parco Nazionale dell' Appennino Tosco-

Emiliano

\section{Secretariat}

Ms Heidrun Frisch-Nwakanma

UNEP/CMS Secretariat

UN Campus

Platz der Vereinten Nationen 1

Germany

heidrun.frisch@cms.int

Tel. +49228 8152491

Ms Tine Lindberg-Roncari

UNEP/CMS Secretariat

UN Campus

Platz der Vereinten Nationen 1

Germany

tine.I-roncari@cms.int

Tel. +49 2288152493 


\section{ANNEX 3: References}

\section{GROUP A}

Amiel, J.J., Bao, S., and Shine, R. (2017). The effects of incubation temperature on the development of the cortical forebrain in a lizard. Animal Cognition 20, 117-125.

Arangio, R. (2012). Minimising whale depredation on longline fishing Australian Toothfish fisheries. Nuffield Australia Project No 1201. Fisheries Research \& Development Corporation and Woolworths. Nuffield, Australia.

Beschta, R.L. \& Ripple, W.J. (2018) Wolf-triggered trophic cascades and stream channel dynamics in Olympic National Park: a comment on East et al. (2017) Earth Surf. Process. Landforms 43, 930-935 (2018). DOI: 10.1002/esp.4289

Bielby, J., Donnelly, C.A., Pope, L.C., Burke ,T. and Woodroffe, R. (2014) Badger responses to small-scale culling may compromise targeted control of bovine tuberculosis. PNAS, 111: 9193 9198; https://doi.org/10.1073/pnas.1401503111

Borg, B. L., Brainerd, S. M., Meier, T. J., Prugh, L. R. and Boutin, S. (2015), Impacts of breeder loss on social structure, reproduction and population growth in a social canid. J Anim Ecol, 84: 177-187. doi:10.1111/1365-2656.12256

Brainerd, S. M., Andrén, H., Bangs, E. E., Bradley, E. H., Fontaine, J. A., Hall, W., et al. (2008). The effects of breeder loss on wolves. Journal of Wildlife Management, 72(1), 89-98. Retrieved from https://search-proquestcom.ezproxy.stir.ac.uk/docview/234227298?accountid=14755

Chiyo, P., Moss, C.J. \& Alberts, S.C. (2012) The Influence of Life History Milestones and Association Networks on Crop-Raiding Behavior in Male African Elephants PloS One 7(2): e31382 doi:10.1371/journal.pone.0031382.t002

East, A.E., Jenkins, K.J., Happe, P.J., Bountry, J.A., Beechie, T. J., Mastin, M.C., Sankey, J.B. \& Randle, T.J. (2017) Channel-planform evolution in four rivers of Olympic National Park, Washington, USA: the roles of physical drivers and trophic cascades. Earth Surf. Process. Landforms 42, 1011-1032. DOI: 10.1002/esp.4048

Fortin, D., Beyer, H.L., Boyce, M.S., Smith, D.W., Duschene, T. \& Mao, J.S. (2005) Wolves influence elk movements; behaviour shapes a tropic cascade in Yellowstone National Park. Ecology 86: 1320-1330. https://doi.org/10.1890/04-0953

Foroughirad, V. \& Mann, J. (2013) Long-term impacts of fish provisioning on the behavior and survival of wild bottlenose dolphins. Biological Conservation 160: 242-249. https://doi.org/10.1016/j.biocon.2013.01.001

Haber, G. C. (1996), Biological, Conservation, and Ethical Implications of Exploiting and Controlling Wolves. Conservation Biology, 10: 1068-1081. doi:10.1046/j.15231739.1996.10041068.x

Kirby, R., Alldredge, M.W. and Pauli, J.N. (2016) The diet of black bears tracks the human footprint across a rapidly developing landscape. Biological Conservation 200: 51-59. https://doi.org/10.1016/j.biocon.2016.05.012

McLennan, M.R. \& Hockings, K.J. (2014) Wild chimpanzees show group differences in selection of agricultural crops. Sci. Rep. 4, 5956

Noble, D.W.A., Byrne, R.W., and Whiting, M.J. (2014). Age-dependent social learning in a lizard. Biology Letters 10, 20140430.

Oriol-Cotterill, A., Valeix, M., Frank, L. G., Riginos, C. and Macdonald, D. W. (2015). Landscapes of Coexistence for terrestrial carnivores: the ecological consequences of being downgraded from ultimate to penultimate predator by humans. Oikos, 124: 12631273. doi:10.1111/oik.02224 
Perrin, W.F. and Mesnick, S.L. 2003. Sexual ecology of the spinner dolphin, Stenella longirostris: geographic variation in mating system. Marine Mammal Science, 19(3): 462-483.

Redpath SM, Young J, Evely A et al (2013) Understanding and managing conservation conflicts. Trends Ecol Evol 28:100-109. doi:10.1016/j.tree.2012.08.021

Ripple W.J. et al. (2014) Status and Ecological Effects of the World's Largest Carnivores Science 343, 1241484. DOI: 10.1126/science.1241484

Rogers, Everett M. (1962). Diffusion of innovations (1st ed.). New York: Free Press of Glencoe. OCLC 254636

Scott M. Brainerd, Henrik Andrén, Edward E. Bangs, Elizabeth H. Bradley, Joseph A. Fontaine, Wayne Hall, Yorgos lliopoulos, Michael D. Jimenez, Elizabeth A. Jozwiak, Olof Liberg, Curt M. Mack, Thomas J. Meier, Carter C. Niemeyer, Hans C. Pedersen, Håkan Sand, Ronald N. Schultz, Douglas W. Smith, Petter Wabakken, and Adrian P. Wydeve. 2008. The Effects of Breeder Loss on Wolves. Journal of Wildlife Management 200872 (1), 89-98

Sinervo, B., Méndez-De-La-Cruz, F., Miles, D.B., Heulin, B., Bastiaans, E., Villagran-Santa Cruz, M., Lara-Resendiz, R., Martínez-Méndez, N., Calderón-Espinosa, M.L., MezaLázaro, R.N., Gadsden, H., Avila, L.J., Morando, M., De La Riva, I.J., Victoriano Sepulveda, P., Duarte Rocha, C.F., IbargüengoytíA, N., Puntriano, C.A., Massot, M., Lepetz, V., Oksanen, T.A., Chapple, D.G., Bauer, A.M., Branch, W.R., Clobert, J., and Sites Jr., J.W. (2010). Erosion of lizard diversity by climate change and altered thermal niches. Science 328, 894-899.

Slotow, R., Gus, v. D., Poole, J., Page, B., \& Klocke, A. (2000). Older bull elephants control young males. Nature, 408(6811),

doi:http://dx.doi.org.ezproxy.stir.ac.uk/10.1038/35044191

425-6.

Wade, P. R., Reeves, R.R. and Mesnick, S.L. 2012. Social and behavioural factors in cetacean responses to overexploitation: Are odontocetes less "resilient" than mysticetes? Journal of Marine Biology, Volume 2012 Article ID 567276, doi:10.1155/2012/567276

Western Wildlife Outreach (2014) Living with Livestock \& Wolves; Wolf-Livestock Nonlethal Conflict Avoidance, A Review of the Literature. https://wdfw.wa.gov/conservation/gray_wolf/livestock/wolf_livestock_conflict_avoidanc e_literature_review_11_2014_final_submitted_version.pdf

Wielgus RB, Peebles KA (2014) Effects of Wolf Mortality on Livestock Depredations. PLoS ONE 9(12): e113505. https://doi.org/10.1371/journal.pone.0113505

Williams, V.L. \& Whiting, M. (2016) A picture of health? Animal use and the Faraday traditional medicine market, South Africa. Journal of Ethnopharmacology 179: 265-273. https://doi.org/10.1016/j.jep.2015.12.024

Wrege, P.H., Rowland, E.D., Keen, S. and Shiu, Y. (2017) Acoustic monitoring for conservation in tropical forests: examples from forest elephants. Methods Ecol. Evol. 8: 1292-1301 DOI: 10.1111/2041-210X.12730

\section{GROUP B}

Aplin, Farine, Morand-Ferron, Cockburn, Thornton, Sheldon (2015) Experimentally induced innovations lead to persistent culture via conformity in wild birds. Nature. 518: 538-541.

Beck BB, Castro MI, Stoinski TS \& Ballou JD. 2002. The effects of prerelease environments and postrelease management on survivorship in reintroduced golden lion tamarins. In DG Kleiman \& AB Rylands (Eds) Lion Tamarins: Biology and Conservation. Washington DC: Smithsonian Institution Press. 
Brown \& Laland (2001) Social learning and life skills training for hatchery reared fish. Journal of Fish Biology 59: 471-493.

Carroll EL, Rayment W, Alexander AM, Baker CS, Patenaude N, Steel D, Constantine R, Cole R, Boren L, Childerhouse S. (2014) Re-establishment of former wintering grounds by New Zealand southern right whales. Marine Mammal Science 30: 206-220

Custance D, Whiten A \& Fredman T. 2002. Social learning and primate reintroduction. International Journal of Primatology 23: 479-499.

Farine, Aplin, Sheldon, Hoppitt (2015) Interspecific social networks promote information transmission in wild songbirds. Proc Roy Soc B. 282: 20142804.

Fisher \& Hinde (1949) The opening of milk bottles by birds. British Birds. 42: 347-357.

Ford, K.B., Ellis, G.M. and Balcomb, K.C. (2000) Killer Whales: The Natural History and Genealogy of Orcinus orca in the Waters of British Columbia and Washington. UBC Press and University of Washington Press, Vancouver, BC and Seattle, WA.

Greggor, A.et al. 2016 Harnessing learning biases is essential for applying social learning in conservation. Behavioral Ecology and Sociobiology 71: 16

Hobaiter, Poisot, Zuberbuehler, Hoppitt, Gruber, T. (2014) Social network analysis shows direct evidence for social transmission of tool use in wild chimpanzees. Plos Biology. 12: 1-12.

Kierulff, M.C.M. et al. 2012 The Golden lion tamarin Leontopithecus rosalia: a conservation success story. International Zoo Yearbook 46: 36-45.

Krützen M, Willems EP, van Schaik CP (2011) Culture and geographic variation in orangutan behavior. Curr Biol21:1808-1812.Kühl, S. et al. (2016). Chimpanzee accumulative stone throwing. Scientific Reports 6, 22219.

Kuhl H. S. et al. (2016) Chimpanzee accumulative stone throwing. Scientific Reports 6, 22219.

Lusseau \& Newman (2004) Identifying the role that animals play in their social networks. Proc Roy Soc B. 271: S477-S481.

Morin, P.A., Archer, F.I., Foote, A.D., Vilstrup, J., Allen, E.E., Wade, P., Durban, J., Parsons, K., Pitman, R., Li, L. \& Bouffard, P. (2010). Complete mitochondrial genome phylogeographic analysis of killer whales (Orcinus orca) indicates multiple species. Genome Research 20(7):908-916.

Mueller, O'Hara, Converse, Urbanek, Fagan (2013) Social learning of migratory performance. Science. 341: 999-1002.

Perry, S. E., Barrett, B. J., \& Godoy, I. (2017). Older, sociable capuchins (Cebus capucinus) invent more social behaviors, but younger monkeys innovate more in other contexts. Proceedings of the National Academy of Sciences, 114(30), 7806-7813.

Petitgas, Secor, McQuinn, Huse, Lo (2010) Stock collapses and their recovery: mechanisms that establish and maintain life-cycle closure in space and time. ICES Journal of Marine Science. 67: 1841-1848.

Pitman, R.L. and Ensor, P. (2003) Three forms of killer whales (Orcinus orca) in Antarctic waters. J. Cetacean Res. Manage., 5, 131-139.

Riesch R, Barrett-Lennard LG, Ellis GM, Ford JKB, Deecke VB (2012) Cultural traditions and the evolution of reproductive isolation: Ecological speciation in killer whales? Biol J Linn Soc Lond 106:1-17.

Robbins MM, Ando C, Fawcett KA, Gruiter CC, Hedwig D, Iwata Y, Lodwick JL, Masi S, Salmi $\mathrm{R}$, Stoinski TS et al (2016) Behavioural variation in gorillas: evidence of potential cultural traits. PLOS ONE 11:e0160483.

Sarrazin, F. and Barbault, R., 1996. Reintroduction: challenges and lessons for basic ecology. Trends in ecology \& evolution, 11: 474-478. 
Seppanen (2007) Social information use is a process across time, space, and ecology, reaching heterospecifics. Ecology. 88: 1622-1633.

Slagsvold \& Wiebe (2007) Learning the ecological niche. Proceedings of the Royal Society BBiological Sciences. 274: 19-23.

Sol D, Arcos JM \& Senar JC. 1995. The influence of refuse tips on the winter distribution of yellow legged gulls. Bird Study 42, 216-221.

Stoinski T, Beck BB, Bloomsmith MA \& Maple TL. 2003. A behavioral comparison of captiveborn, reintroduced golden lion tamarins and their wild-born offspring. Behaviour 140, 137-160.

Urbanek, R.P. et al. 2010 Winter release and management of reintroduced migratory Whooping Cranes Grus americana. Bird Conservation International 20: 43-54.

Vaidyanathan, G. (2011) The cultured chimpanzees. Do chimpanzees have traditions? As wild populations dwindle, researchers are racing to find out. Nature, 476, 266-269.

van Schaik CP, Ancrenaz M, Borgen G, Galdikas B, Knott CD, Singleton I, Suzuki A, Utami, SS, Merrill, M (2003) Orangutan cultures and the evolution of material culture. Science 299:102-105.

White et al. 2012. Psittacine reintroductions: Common denominators of success. Biological Conservation 148: 106-115.

Whiten, A. (2005). The second inheritance system of chimpanzees and humans. Nature, 437, 52-55.

Whiten, A. (2015). Experimental studies illuminate the cultural transmission of percussive technology in Homo and Pan. Phil. Trans. R. Soc. B, 370, 20140359.

Whiten, A. (2017a) A second inheritance system: The extension of biology through culture. Royal Society Interface Focus 7, 20160142.

Whiten, A. (2017b) How culture extends the scope of evolutionary biology in the great apes. Proc. Natl. Acad. USA 114, 7790-7797.

Whiten A, Goodall J, McGrew WC, Nishida T, Reynolds V, Sugiyama Y, Tutin CEG, Wrangham RW, Boesch C 1999 Cultures in chimpanzees. Nature 399:682-685

Whiten, A., Schick, K. \& Toth, N. (2009). The evolution and cultural transmission of percussive technology: integrating evidence from paleoanthropology and primatology. Journal of Human Evolution, 57, 420-435.

Yamakoshi, G. 1998 Dietary responses to food scarcity of wild chimpanzees at Bossou, Guinea: Possible implications for ecological importance of tool use. Am J Phys Anthropol 106: 283-295.

\section{GROUP C}

Ackerman JT, Takekawa JY, Orthmeyer DL, Fleskes JP, Yee JL, Kruse KL (2006). Spatial use by wintering greater white-fronted geese relative to a decade of habitat change in California's Central Valley. J Wildl Manage 70: 965-976.

Adams JR, Kelly BT, Waits LP (2003). Using faecal DNA sampling and GIS to monitor hybridization between red wolves (Canis rufus) and coyotes (Canis latrans). Mol Ecol 12: 2175-2186.

Allee W (1931). Animal Aggregations. Chicago Press: Chicago.

Allen J, Weinrich M, Hoppitt W, Rendell L (2013). Network-based diffusion analysis reveals cultural transmission of lobtail feeding in humpback whales. Science (80) 340: 485-488.

Allendorf FW, Leary RF, Spruell P, Wenburg JK (2001). The problems with hybrids: Setting conservation guidelines. Trends Ecol Evol 16: 613-622. 
Anile S, Ragni B, Randi E, Mattucci F, Rovero F (2014). Wildcat population density on the Etna volcano, Italy: A comparison of density estimation methods. J Zool 293: 252-261.

Arandjelovic M, Vigilant $L$ (2018). Non-invasive genetic censusing and monitoring of primate populations. Am J Primatol 80: :e22743.

Benson JF, Patterson BR, Wheeldon TJ (2012). Spatial genetic and morphologic structure of wolves and coyotes in relation to environmental heterogeneity in a Canis hybrid zone. Mol Ecol 21: 5934-5954.

Bluff LA, Kacelnik A, Rutz C (2010). Vocal culture in New Caledonian crows (Corvus moneduloides). Biol J Linn Soc 101: 767-776.

Brown C, Laland K (2001). Social learning and life skills training for hatchery reared fish. $J$ Fish Biol 59: 471-493.

Caniglia R, Fabbri E, Galaverni M, Milanesi P, Randi E (2014). Noninvasive sampling and genetic variability, pack structure, and dynamics in an expanding wolf population. $J$ Mammal 95: 41-59.

Carroll EL, Baker CS, Watson M, Alderman R, Bannister JL, Gaggiotti OE, et al. (2015). Cultural traditions across a migratory network shape the genetic structure of southern right whales around Australia and New Zealand. Sci Rep 5: 16182.

Carroll EL, Bruford MW, Dewoody JA, Leroy G, Strand A, Waits L, et al. (2018). Genetic and genomic monitoring with minimally invasive sampling methods. Evol Appl: DOI: 10.1111/eva.12600.

Clapham P, Aguilar A, Hatch LT (2008). Determining spatial and temporal scales for management of cetaceans: lessons from whaling. Mar Mammal Sci 24: 183-201.

Courchamp F, Clutton-Brock T, Grenfell B (1999). Inverse density dependence and the Allee effect. Trends Ecol Evol 14: 405-410.

Eizaguirre C, Baltazar-Soares M (2014). Evolutionary conservation-evaluating the adaptive potential of species. Evol Appl 7: 963-967.

Foote A, Vijay N, Avila-Arcos M, Baird R, Durban J, Morin P, et al. (2016). Genome-culture coevolution promotes rapid divergence in the killer whale. bioRxiv: 1-48.

Fox AD, Hilmarsson J, Einarsson, Walsh AJ, Boyd H, Kristiansen JN (2002). Staging site fidelity of greenland white-fronted geese anser albifrons flavirostris in iceland. Bird Study 49: 42-49.

Gilbert M, Watson RT, Ahmed S, Asim M, Johnson JA (2007). Vulture restaurants and their role in reducing diclofenac exposure in Asian vultures. Bird Conserv Int 17: 63-77.

Griffin AS (2004). Social learning about predators: a review and prospectus. Anim Learn Behav 32: 131-140.

Harrison X, Tregenza T, Inger R, Colhoun K, Dawson D, Gudmundsson G, et al. (2010). Cultural inheritance drives site fidelity and migratory connectivity in a long-distance migrant. Mol Ecol 19: 5484-5496.

Hobaiter C, Poisot T, Zuberbühler K, Hoppitt W, Gruber T (2014). Social Network Analysis Shows Direct Evidence for Social Transmission of Tool Use in Wild Chimpanzees. PLoS Biol 12: e1001960.

Hoppitt, W. J. E., James R., Anderson, J. A., Masuda, B. M. and C. Rutz. In prep. Managing animals' social knowledge in a conservation context. [Invited 'Opinion Article' for Trends in Ecology and Evolution]

Houston D, Piper SE (Eds.) (2006). Proceedings of the international conference on conservation and management of vulture populations. 14-16 November 2005, Thessaloniki, Greece. Natural History Museum of Crete \& WWF Greece. 176 pages.

Hussey NE, Kessel ST, Aarestrup K, Cooke SJ, Cowley PD, Fisk AT, et al. (2015). Aquatic animal telemetry: A panoramic window into the underwater world. Science 348: 1221. 
Indigo N, Smith J, Webb JK, Phillips B (2018). Not such silly sausages: Evidence suggests northern quolls exhibit aversion to toads after training with toad sausages. Austral Ecol: doi:10.1111/aec.12595.

Jackson AL, Ruxton GD, Houston DC (2008). The effect of social facilitation on foraging success in vultures: a modelling study. Biol Lett 4: 311-313.

Kays R, Crofoot MC, Jetz W, Wikelski M (2015). Terrestrial animal tracking as an eye on life and planet. Science 348: 1222.

Keith SA, Bull JW (2017). Animal culture impacts species' capacity to realise climate-driven range shifts. Ecography (Cop) 40: 296-304.

Kraus SD, Rolland RM (Eds.) (2007). The urban whale: North Atlantic right whale at the cross roads. Harvard University Press: Cambridge, Massachussetts, USA.

Krause J, Krause S, Arlinghaus R, Psorakis I, Roberts S, Rutz C (2013). Reality mining of animal social systems. Trends Ecol Evol 28: 541-551.

Lacy RC, Williams R, Ashe E, Balcomb KC, Brent LJN, Clark CW, et al. (2017). Evaluating anthropogenic threats to endangered killer whales to inform effective recovery plans. Sci Rep 7: 14119 |.

Morin P, Parsons KM, Archer FI, Ávila-Arcos MC, Barrett-Lennard LG, Dalla Rosa L, et al. (2015). Geographical and temporal dynamics of a global radiation and diversification in the killer whale. Mol Ecol 24: 3964-3979.

O'Corry-Crowe G, Suydam R, Quakenbush L, Potgieter B, Harwood L, Litovka D, et al. (2018). Migratory culture, population structure and stock identity in North Pacific beluga whales (Delphinapterus leucas). PloS One 13: e0194201

Riesch R, Barrett-Lennard LG, Ellis GM, Ford JKB, Deecke VB (2012). Cultural traditions and the evolution of reproductive isolation : ecological speciation in killer whales ? Biol J Lin Soc 106:: 1-17.

Stefánsson, J.H., K. Hermannsdóttir \& S. Guơmundsson (2015): Helsingjar í Austur-Skaftafellssýslu - Stofnstærð og varpútbreið̌sla 2014. - Höfn í Hornafirði, Náttúrustofa Suðausturlands.

Stephens, P. A., Sutherland, W. J. and Freckleton, R. P. 1999. What is the Allee Effect?. Oikos, 87: 185-190.

Steyer K, Kraus RHS, Mölich T, Anders O, Cocchiararo B, Frosch C, et al. (2016). Large-scale genetic census of an elusive carnivore, the European wildcat (Felis s. silvestris). Conserv Genet 17: 1183-1199.

Ward-Fear G, Pearson DJ, Brown GP, Rangers B, Shine R (2016). Ecological immunization: in situ training of free-ranging predatory lizards reduces their vulnerability to invasive toxic prey. Biol Lett 12: 20150863.

Zimmer WMX (2011). Passive acoustic monitoring of cetaceans. Cambridge University Press: Cambridge, Massachussetts, USA.

\section{GROUP D}

Aplin, Farine, Morand-Ferron, Cockburn, Thornton, Sheldon (2015) Experimentally induced innovations lead to persistent culture via conformity in wild birds. Nature. 518: 538-541.

Aplin, Sheldon, McElreath (2017) Conformity does not perpetuate suboptimal traditions in a wild population of songbirds. PNAS 114:7830-7837.

Arandjelovic M, Vigilant $L$ (2018) Non-invasive genetic censusing and monitoring of primate populations. American Journal of Primatology. e22743

Baker, C. S., Steel, D., Calambokidis, J., Falcone, E., Gozález-Peral, U., Barlow, J., Burdin, A. M., Clapham, P. J., Ford, J. K. B., Gabriele, C. M., Mattila, D., Rojas-Bracho, L., 
Straley, J. M., Taylor, B. L., Urbán R., J., Wade, P. R., Weller, D., Witteveen, B. H., Yamaguchi, M. (2013). Strong maternal fidelity and natal philopatry shape genetic structure in an oceanic population of whales. Marine Ecology Progress Series 494:291306.

Bastian, M. L., Zweifel, N., Vogel, E. R., Wich, S. A. and van Schaik, C. P. (2010), Diet traditions in wild orangutans. Am. J. Phys. Anthropol., 143: 175-187.

Cantor, M., Whitehead, H., Gero, S., Rendell., L. (2016). Cultural turnover among Galápagos sperm whales. R. Soc. Open Sci. 3:160615.

Carroll, E. L., C. S. Baker, M. Watson, R. Alderman, J. Bannister, O. E. Gaggiotti, D. R. Gröcke, N. Patenaude \& R. Harcourt. (2015). Cultural traditions across a migratory network shape the genetic structure of southern right whales around Australia and New Zealand. Sci. Rep. 5, 16182.

Ciucci, P., Boitani, L., Falco, M. and Maiorano, L. (2018), Hierarchical, multi-grain rendezvous site selection by wolves in southern Italy. Jour. Wild. Mgmt. doi:10.1002/jwmg.21440

Ford, J.K.B., and Ellis, G.M. 2006. Selective foraging by fish-eating killer whales Orcinus orca in British Columbia. Marine Ecology Progress Series 316: 185-199

Ford, J.K.B., and Ellis, G.M. 1999. Transients: Mammal-Hunting Killer Whales of British Columbia, Washington, and Southeastern Alaska. UBC Press, Vancouver, and U. of Washington Press, Seattle. $96 \mathrm{pp}$

Ford, J.K.B., Ellis, G.M. and Balcomb, K.C. 2000. Killer Whales: The Natural History and Genealogy of Orcinus orca in British Columbia and Washington. Second Edition. UBC Press, Vancouver, and U. of Washington Press, Seattle. 102 pp

Keith, S. A. and J. W. Bull (2017). "Animal culture impacts species' capacity to realise climatedriven range shifts." Ecography 40: 296-304.

O'Corry-Crowe, G., R. Suydam, L. Quakenbush, B. Potgieter, L. Harwood, D. Litovka, T. Ferrer, J. Citta, V. Burkanov, K. Frost, and B. Mahoney. 2018. Migratory culture, population structure and stock identity in North Pacific beluga whales (Delphinapterus leucas). PLOS ONE 13(3):e0194201.

Wade, P.R., Reeves, R.R., Mesnick, S.L. (2012) Social and Behavioural Factors in Cetacean Responses to Overexploitation: Are Odontocetes Less "Resilient" Than Mysticetes? Journal of Marine Biology 2012: 1-15.

Warner, R.R., 1988. Traditionality of mating-site preferences in a coral reef fish. Nature, 335(6192), p.719.

Whitehead, H., \& Rendell, L. (2004). Movements, habitat use and feeding success of cultural clans of South Pacific sperm whales. Journal of Animal Ecology, 73: 190-196

Whiten, A. 2015. Experimental studies illuminate the cultural transmission of percussive technology in Homo and Pan. Phil. Trans. R. Soc. B, 370, 20140359. 